\title{
When the killing has been done: Influences of personality on third-party judgment and punishment of homicides in moral dilemma scenarios
}

\author{
Alexander Behnke ${ }^{1^{*}}$, Anja Strobel ${ }^{2}$, Diana Armbruster ${ }^{1^{*}}$ \\ ${ }^{1}$ Department of Psychology, Technische Universität Dresden, 01062 Dresden, Germany; ${ }^{2}$ Department of Psychology, \\ Chemnitz University of Technology, 09120 Chemnitz, Germany
}

\begin{abstract}
Killing people is universally considered reprehensible and evokes in observers a need to punish perpetrators. To investigate how observers' personality influences their cognitive, emotional, and punishing reactions towards perpetrators, we analyzed data from 1,004 participants who responded to three scenarios describing deliberate killings from a third-party perspective. Utilitarian motive of killing and inevitability of harm varied systematically between scenarios. Participants' moral appropriateness judgments, emotions towards perpetrators, and assigned punishments revealed complex scenario-personality interactions. Trait psychopathy led to more understanding emotions but harsher punishments in all scenarios. Regarding utilitarian killings, need for cognition led to milder punishments, whereas intuitive/authority-obedient thinking led to stronger negative emotions and harsher punishments. Other-oriented empathy, trait anxiety, and justice sensitivity did not account for differences in third-party punishments. Our findings highlight the importance of interindividual differences on moral decision making and sense of justice.
\end{abstract}

Keywords: moral dilemma, third-party punishment, personality traits, need for cognition, moral emotions, inevitability of harm, utilitarian judgment, trait psychopathy, authoritarianism, person-situation interaction

\section{Introduction}

Monitoring compliance with rules of social coexistence and punishing their violation are essential for the stability of human societies. Especially in growing and increasingly anonymous societies, uninvolved third parties play a central role in restoring and enforcing rule compliance (Bendor and Swistak, 2001; Boyd et al., 2003). When observing violations of socio-moral rules resulting in negative consequences for victims, third parties typically sense a strong obligation to punish perpetrators and/or try to compensate victims in order to restore justice. This "altruistic" motivation to punish arises although observers themselves are not negatively affected and although they have no direct benefit from punishing perpetrators (Fehr and Fischbacher, 2004; Fehr and Gächter, 2002). In fact, the evaluation of rule transgressions by uninvolved third parties (e.g., neutral judges or lay assessors) is a basic principle of most legal systems.

When evaluating rule transgressions, third parties may take into account the intentions or goals of perpetrators as well as possible situational constraints under which perpetrators acted (Carlsmith et al., 2002; Cushman, 2008). However, due to differences in available information or lack of personal consequences the perception of justice and moral inappropriateness may vary considerably with different so- cial perspectives (e.g., Baumert and Schmitt, 2016; DeScioli and Kurzban, 2009). There are numerous potential modulators that could constrain whether third parties judge a rule transgression as inappropriate and how they punish the agent and/or try to compensate the victim (Cushman, 2008; DeScioli et al., 2011; Molenmaker et al., 2014). In this study, we focus on the question whether and how personality traits influence observers' responses towards acts of killing. We explore how personality traits previously associated with moral decision making, moderate i) emotional reactions of observers, ii) assessment of moral appropriateness, and iii) severity of the punishment imposed. That is, we investigate whether personality traits are associated with a different sensitivity of observers to situational constraints and motives to kill.

\subsection{Thou shalt not kill}

The condemnation of killing as stated, for instance, by the $5^{\text {th }}$ commandment (God, in Exodus $20: 13,6^{\text {th }}$ century BC), is one of the most important moral principles in basically all human societies (e.g., Antonenko Young et al., 2013; Graham et al., 2011). Although this moral imperative clearly forbids the murder of fellow human beings, exceptions to this rule exist. Various reasons have been brought forward to justify killing others. Examples include self-defense, capital punishment, or warfare. Under

\footnotetext{
* Correspondence concerning this article should be addressed at Alexander Behnke or Dr. Diana Armbruster, Differential and Personality Psychology, Department of Psychology, Technische Universität Dresden, D-01062 Dresden, Germany; Phone: +49 351 463-32528; Fax: +49 351 463-36993.

E-mail addresses: Alexander Behnke (https://orcid.org/0000-0002-4128-9627): alexander.behnke@tudresden.de; Anja Strobel (https://orcid.org/0000-0002-0313-0615): anja.strobel@psychologie.tu-chemnitz.de; Diana Armbuster (https://orcid.org/0000-0001-8649-6227): diana.armbruster@tu-dresden.de.
} 
these circumstances, observers could consider violating the general condemnation of killing to be relatively appropriate and therefore punish perpetrators for killing less severely or not at all.

Moral dilemmas provide a standardized method to experimentally investigate how different situational characteristics determine whether the killing of another person is deemed morally permissible and therefore not (or less) punishable (Christensen and Gomila, 2012; Mikhail, 2007). The hypothetical short stories describe scenarios with two possible mutually exclusive outcomes, both violating essential moral principles (Foot, 1967; Hauser et al., 2007; Quinn, 1989). So far, moral dilemma research predominantly investigated judgment behavior from the first-party perspective (e.g., whether participants would kill a person under certain circumstances) (Cushman et al., 2006; Greene et al., 2001, 2004, 2009; Hauser et al., 2007). Various situational features were identified to influence moral decision making, including use of personal force or evitability and intentionality of harm (Christensen et al., 2014; Christensen and Gomila, 2012; Waldmann et al., 2012). There are considerably less studies on the third-party perspective, in which participants judge whether the choice of another person is morally adequate. Some studies reported different moral responses in first vs. third parties (Nadelhoffer and Feltz, 2008; Tassy et al., 2013b), while others observed no differences (Hauser et al., 2007; Lombrozo, 2009).

In this study, we compared three scenarios, all of which describe the active killing of one or a few individuals (as opposed to death due to neglect). Thus, they are in strong violation of the rule not to kill. However, they vary in two critical features (cf. Christensen et al., 2014): (a) the reason for killing (selfishness vs. utilitarian motive, i.e. saving multiple people by sacrificing one or a few), and (b) the evitability of the victims' death.

From the perspective of moral decision making, the $5^{\text {th }}$ commandment constitutes a deontic rule. Such rules define fundamental principles of right and wrong actions (or inactions) independent of their effect on the "greater good". In contrast, utilitarian (or consequentialist) principles focus on the consequences of these actions. These two principles have been proposed to vie for influence when making moral decisions (Christensen and Gomila, 2012; Foot, 1967; Quinn, 1989). Depending on the situation, they are not necessarily in conflict with each other (Conway and Gawronski, 2013). However, in the case of killing for self-interest, the deontic rule is violated without producing a benefit for the majority. If a small number of individuals are killed in order to protect a larger group, there is a conflict between deontic and utilitarian rules. If observers recognize that perpetrators acted from a utilitarian motive they are expected to punish perpetrators more mildly.

In addition, observers are likely to take into account general circumstances that make the death of victims inevitable, regardless of measure chosen. In such situations, the utilitarian principle might indeed offer an acceptable solution even if the deontic rule is violated: try to safe as many people as possible while sacrificing as little as needed instead of refraining from intervening altogether which results in the death of all (Mikhail, 2007). In fact, previous studies reported that observers consider harmful utilitarian actions more permissible when harm to the victim is inevitable (Moore et al., 2008). Thus, observers are expected to punish utilitarian killings less severely if the general circumstances made the victims' death inevitable.

Third-party judgement and punishment behavior is accompanied or even mediated by cognitive processes and moral emotions (Fiske and Tetlock, 1997; Greene et al., 2004; Waldmann et al., 2012). While some authors highlight the role of deliberate cognitions, others put greater emphasis on intuitive emotional tendencies (moral sentiments; for a review see Waldmann et al., 2012). Nevertheless, cognition and emotion appear to affect moral judgement in a complex interlinked way. Third parties give harsher punishments if the immoral behavior is deemed more reprehensible and when greater harm or unfairness is inflicted on victims. They also report stronger negative emotions like anger, contempt, disgust or disappointment towards perpetrators (e.g., Batson et al., 2007; Carlsmith et al., 2002; Fehr and Fischbacher, 2004; Fiske and Tetlock, 1997; Haidt, 2003; Hopfensitz and Reuben, 2009). In turn, stronger negative emotions facilitate harsher punishment (Carlsmith et al., 2002; Fehr and Fischbacher, 2004; Fiske and Tetlock, 1997; Lotz et al., 2011b; Nelissen and Zeelenberg, 2009; Stouten et al., 2006), indicating that the effect of observed harm or unfairness on third-party punishment could be mediated by negative emotions (McCall et al., 2014; Seip et al., 2014; Wang et al., 2011). So far, most studies focused on single, predominantly negative emotions. However, ambiguous situations result in a complex mixture of partly conflicting emotions including positive notions like sympathy, comprehension or compassion (Haidt, 2003; Horne and Powell, 2016; Rudolph and Tscharaktschiew, 2014; Skoe et al., 2002). Positive emotions towards perpetrators have been reported to result in weakened negative emotions and milder punishment (Condon and DeSteno, 2011; McCall et al., 2014; Valdesolo and DeSteno, 2006).

In sum, observers are expected to show a clear pattern of intensive negative emotions, but hardly understanding emotions towards perpetrators who kill for selfishness. In addition, observers are expected to judge such actions as more morally inappropriate and to severely punish them. In contrast, in the case of utilitarian killings as well as killings of victims, who could not have been saved anyway, observers are expected to feel negative and understanding emotions towards the perpetrators. The ambiguous emotional state is expected to be accompanied by less clear judgements of moral appropriateness and eventually, milder punishments. 


\subsection{Personality traits associated with moral deci- sion making.}

Various personality traits have been associated with justice perception, helping behavior, and moral decision making. Empathy enables people to share the affective state of victims. To morally evaluate hypothetical actions, participants put themselves at the receiving end of the action (cognitive empathy) and experience what victims would experience (affective empathy) (Batson et al., 1995; Miller and Cushman, 2013). Thus, in moral dilemmas, empathic individuals may develop a strong emotional discomfort by being emotionally involved with the fate of threatened individuals as well as by imagining the harmful act itself (Miller et al., 2014). Previous studies with first-party-perspective scenarios found more unpleasant feelings during decision making linked to higher scores of other-oriented empathy, particularly empathic concern and perspective taking. In addition, less utilitarian and more deontic decisions were made (Choe and Min, 2011; Conway and Gawronski, 2013; Gleichgerrcht and Young, 2013; Mcllwain et al., 2012; Patil and Silani, 2014).

Experiencing warmth, compassion, and concern for others in need is considered to promote a true altruistic motivation with the final goal to increase others' welfare. Since its introduction in the $19^{\text {th }}$ century, the definition of altruism has undergone several modifications (Batson and Powell, 2003). Broadly, it refers to the tendency to place the needs of others above one's own. Altruism was suggested to induce uninvolved third parties to put effort in costly punishments of moral transgressions with no or little direct benefit for those who punish (Fehr and Fischbacher, 2003). So far, trait altruism has not been investigated in the context of third-party punishment.

Adopting a victim's perspective can elicit negative emotional distress in third parties by empathizing with victims' suffering or by imagining perpetrators performing harmful actions (Cushman et al., 2012; Sarlo et al., 2014). Individuals characterized by the empathy trait personal distress and trait anxiety (i.e. neuroticism) tend to feel anxious and uncomfortable in tense interpersonal settings and report lower selfesteem (Batson et al., 1987; Davis, 1983). Moreover, when confronted with others' suffering, they tend to adopt an emotional self-focus (self-oriented empathy), characterized by feelings of fear, discomfort or shame. To end their own negative empathic affect, such individuals tend to help quickly or-even more often-to evade the situation resulting in less prosocial behavior (Batson et al., 1987; Haidt, 2003; Sarlo et al., 2014). In first-party-perspective moral scenarios, personal distress was associated with less utilitarian moral decisions (Sarlo et al., 2014). It has been speculated that individuals with experiencing empathic distress avoid intense deliberations to reduce negative feelings caused by the suffering of others, and quickly chose deontic judgments (Sarlo et al., 2014).

In research on social rule transgressions, $p s y$ chopathy is one of the most prominent potential in- fluence factors. Characteristic sub-traits of psychopathy include lack of remorse or guilt, shallow affect, callousness, manipulative tendencies and antisocial behavior (Blair et al., 2013; Decety and Yoder, 2015; Patil, 2015). Psychopaths' deviant behavior was linked to deficits in judging the permissibility of actions in moral dilemmas (Bartels and Pizarro, 2011; e.g., Patil, 2015; Young et al., 2012). Still, other studies reported that psychopaths are capable of accurately identifying immoral (mostly utilitarian) actions, but nevertheless consistently prefer them (e.g., Cima et al., 2010; Schaich Borg et al., 2013; Tassy et al., 2013a). One explanation is that psychopaths choose utilitarian actions because of their lack of empathic concern for potential victims (Blair et al., 2013). Previous studies found that disrespect for deontic rules was accompanied by reduced aversive emotional responses to witnessing or inflicting harm (Patil, 2015), which might be due to reduced empathy for victims or individuals in need (Aharoni et al., 2011; Glenn et al., 2009a, 2009b; Mcllwain et al., 2012; Seara-Cardoso et al., 2012, 2013). The absence of empathic concern for others was linked to less moral-reconstituting anger in observers when witnessing unfair treatment of others (Batson et al., 2007). Based on these findings, it is expected that third parties with higher trait psychopathy tend to accurately consider homicides as morally wrong, but nevertheless feel less aversive emotions and thus punish perpetrators less severely, especially in case of killings with utilitarian motives.

A further relevant personality concept is justice sensitivity, which refers to the individual inclination of perceiving injustice or unfairness from such different social perspectives as being a victim, perpetrator, observer or beneficiary (Baumert and Schmitt, 2016). Observer and perpetrator sensitivity were consistently associated with fairness behavior (i.e. other-oriented justice sensitivity) (Fetchenhauer and Huang, 2004). Individuals with higher other-oriented justice sensitivity rated immoral behavior in moral dilemmas as less permissible and showed more empathic concern and perspective taking as well as lower trait psychopathy (Decety and Yoder, 2015). Moreover, observer justice sensitivity was associated with increased third-party punishment and accompanying feelings of anger (Lotz et al., 2011a). Conversely, victim sensitivity was linked to egocentric justice concerns, while ignoring unfairness affecting others (i.e. self-oriented justice sensitivity) (Fetchenhauer and Huang, 2004).

Furthermore, there is a number of studies suggesting the thinking styles Need for Cognition (NFC) and Faith in Intuition (FI) (Epstein et al., 1996) as relevant personality variables for moral behavior (Strobel et al., 2017): There is evidence for a positive relationship between deliberative thinking styles like NFC and more utilitarian judgment (Conway and Gawronski, 2013; Paxton and Greene, 2010). Other studies report associations of NFC to different aspect of moral attitudes or behavior, respectively (Kinnunen and Windmann, 2013; McClaren et al., 2009; 
Mussel et al., 2013; Strobel et al., 2017). The state of research concerning FI is less conclusive: Bartels (2008) found a factor including FI and NFC to influence the participants' inclination for deontic and utilitarian decisions, respectively. However, other studies could not establish a connection of FI to moral behavior (Conway and Gawronski, 2013; Strobel et al., 2017). Sargent (2004) observed less support for punitive responses to crime by individuals with high NFC scores. The effect was mediated by attributional complexity, suggesting that high-NFC individuals endorse to a higher extent the complexity of perpetrators' motives, reasons, and situational constraints when judging behavior. Thus, if observers are unable or unwilling to mobilize the cognitive effort to deliberate perpetrators' situation and motives, they rely on situationally invariant deontic judgment templates.

Similarly, individuals with authority-obedient mindsets were found to be less likely to examine or integrate more than one perspective on a (moral) problem, especially when it comes to questions concerning existential issues such as life and death (Hunsberger et al., 1994). Rather they "solved" moral problems through a quick and situationally invariant application of deontic moral rules (e.g., Antonenko Young et al., 2013; Conway and Gawronski, 2013; Hunsberger et al., 1994; Kimhi, 2014; Szekely et al., 2015). In general, authority-obedient individuals tend to feel pronounced aggressive feelings towards violators of deontic norms and to impose harsher sanctions on them (Lerner et al., 1998).

Based on these findings the following traits were investigated regarding their influence on thirdparty punishments: other- and self-oriented empathy, altruism, trait anxiety and self-esteem, trait psychopathy, other- and self-oriented justice sensitivity, the thinking styles NFC and FI as well as obedience to authorities. Several of them have conceptual similarities and were reported to systematically correlate. Thus, we aimed at extracting higher-order personality factors from the single traits. So far, no studies investigated the influence of such a broad set of personality traits on the assessment and punishment of homicides by third parties. Thus, the main aim of this study was exploring the interplay between scenario characteristics (i.e., utilitarian motive to kill, preventability of victims' death) and personality differences on third parties' cognitive, emotional, and punitive reactions towards acts of killing.

\section{Methods}

\subsection{Participants}

Data was available from $N=1004$ participants (534 women, 470 men) mainly aged between 22 and 27 years $(M d n \pm Q D=24.5 \pm 2.3$, range 18.1-58.0). The sample primarily comprised native German speakers $(97.6 \%)$. The majority were high-school graduates (99.1\% achieved the German Abitur) who were either currently enrolled as university students $(62.2 \%)$ or had already graduated from university
(31.3\% with Diplom or Master's degree). The remaining participants $(5.9 \%)$ were undergoing vocational job trainings. The sample included all academic disciplines, with a low proportion of psychology students $(7.1 \%)$. With regard to religious belief, $52.8 \%$ considered themselves atheist or agnostic, $37.1 \%$ Christian (including 23.8\% Protestants and $12.4 \%$ Catholics) and $6.9 \%$ as adhering to other beliefs, mainly Buddhism and natural religions.

\subsection{Procedure}

This study was conducted as part of a broader research project. The study concept was approved by the Technische Universität Dresden ethics committee (proposal no. EK241062016). Participants were recruited via social media announcements and invitation emails in distribution lists of several Germanspeaking European universities and the German National Academic Scholarship Foundation. A link took interested participants to a two-stage online survey (LimeSurvey $\mathrm{GmbH}$, 2017). Before entering the survey, participants were informed about general study procedures and aims and indicated informed consent by clicking a checkbox. In the first survey session, participants completed sociodemographic and personality questionnaires. One week later, they received an invitation to the second survey session, during which they read short fictitious scenarios about differentially morally permissible actions. Participants were asked to rate their emotional response and to judge the behavior of the scenarios' protagonists. The entire survey took between $30-60$ minutes to complete.

\subsection{Experimental design}

Due to the high content heterogeneity of frequently used moral dilemmas, aggregating several dilemmas as one condition category causes unwanted error variance (see Christensen et al., 2014 for details). Therefore, we limited this study to the consideration of two clearly defined condition differences of killing behavior that could be examined using three specific scenarios. The three moral dilemmas lifeboat, footbridge, and architect (Greene et al., 2008; Koenigs et al., 2007) were rephrased in the third-person perspective (see Supplementary Material). (i) Comparing the architect with the footbridge scenario allowed investigating the inclination of third parties to regard perpetrators' utilitarian motive as mitigating factor. The architect scenario presented a killing due to sheer selfishness: An architect pushed his boss from a scaffold to his death because he had been repeatedly treated rudely by him. The killing violates deontic and utilitarian rules simultaneously (i.e. congruent transgression; see Conway and Gawronski, 2013) and is expected to be universally condemned by third parties. In contrast, the footbridge scenario presents an incongruent scenario (Conway and Gawronski, 2013), in which the two moral principles imply different courses of action: The protagonist decided to push a large stranger from a footbridge on a railway track in order to block the 
course of an approaching trolley that otherwise would have crushed five railway workers to death. The presented action is in line with the utilitarian principle to minimize the total harm while at the same time violating the deontic rule not to kill.

(2) The footbridge scenario was compared with the lifeboat scenario to investigate whether third parties consider the inevitability of the death of those killed as mitigating factor when judging and punishing perpetrators (Moore et al., 2008). In the footbridge scenario, the killing of the one person is entirely preventable-but would result in the death of five others. However, in the lifeboat scenarios death is inevitable regardless of the chosen action: Crew and passengers of a cruise ship sinking in the Arctic Ocean saved themselves into lifeboats. However, the overcrowded lifeboats are about to sink due to rising waves resulting in the death of everyone in the lifeboat. Therefore, a senior officer decided to push some people overboard so that at least the remaining occupants can survive.

All participants read and responded to all scenarios providing within-subject comparisons. After an exercise scenario familiarizing participants with the procedure and input mask for their responses, fifteen scenarios were presented, including the three scenarios examined in this study and two scenarios addressing another research question on utilitarian rule transgressions (epidemic, vaccine policy; manuscript in prep.). To avoid carry-over effects (Wiegmann and Waldmann, 2014), the scenarios planned to contrast were not presented directly after another but were embedded in a randomly chosen series of ten filler scenarios presenting a great heterogeneity of situational and moral settings (see Supplement for details).

After reading each scenario, participants rated the intensity of their emotions towards the scenario's protagonist on 7-point Likert scales ranging from 0 (not at all) to 6 (very intensive). A total of seven emotional items was presented. The four items (1) anger/outrage, (2) contempt, (3) moral disgust, and (4) disappointment were averaged to negative/hostile emotions (Cronbach's $\alpha=.88, .89$, and .91 in architect, footbridge, and lifeboat scenario). The emotional items (1) comprehensive affection, (2) sympathy, and (3) compassion/pity were averaged to the scale of understanding emotions (Cronbach's $\alpha=.84, .84$, and .82 in architect, footbridge, and lifeboat scenario). Afterwards, participants rated how morally appropriate they considered the described action on a 7point Likert scale ranging from 0 (completely disagree) to 6 (completely agree). Finally, participants decided whether and how long perpetrators should be imprisoned. Imprisonment length could be freely set with a slider within the limits of 0 to 100 years. Other types of punishment (e.g., fines, community work or death penalty) could not be imposed. Participants also rated whether it was difficult to reach a judgement in the respective scenarios on a 7-step Likert scale ranging from 0 (completely disagree) to 6 (completely agree). There was no time limit for read- ing the scenario or answering the items.

\subsection{Assessment of personality}

Personality traits were assessed using validated scales. However, to keep processing time for participants within reasonable limits, we applied-if available-short inventories and cleared inventories from scales not relevant for the research question. Trait psychopathy were assessed with a German version of the Self-Report Psychopathy scale, version III (SRPIII; Williams et al., 2003). Three of the four SRP-III scales were administered, namely interpersonal manipulation, callous affect, and erratic lifestyle with 16 items each (Cronbach's $\alpha=.79, .77$, and .74, respectively). The fourth scale (antisocial behavior) was omitted because investigations in community samples revealed extremely low means and very little variance. Thus, resulting extremely right-skewed trait scores would have had to be excluded from the subsequent exploratory factor analysis. Using the German Interpersonal Reactivity Index (IRI-SPF; Paulus, 2009), other-oriented empathy was assessed with the three scales fantasy, empathic concern, and perspective taking, whereas self-oriented empathy was assessed with the scale personal distress (Cronbach's $\alpha$ $=.73, .73, .75$, and .67 , respectively, with four items each). Note that the personal distress scale typically has a lower internal consistency (Paulus, 2014). Altruism was assessed using the respective facet scale of the German NEO Personality Inventory-Revised (NEO-PI-R; Ostendorf and Angleitner, 2004) (Cronbach's $\alpha=.73$ ). The traits need for cognition and faith in intuition were assessed according to the Cognitive-Experiential Self-Theory (Epstein et al., 1996) using the German Rational-Experiential Inventory (REI; Keller et al., 2000) (Cronbach's $\alpha=.84$ and .85, respectively). Justice sensitivity (Baumert and Schmitt, 2016) was assessed by administering the Injustice Sensitivity-Short Scales (USS-8; Beierlein et al., 2013). On four scales, the inventory differentiates participants' inclination to experience injustice from the four social perspectives victim, perpetrator, beneficiary, and observer. Cronbach's $\alpha$ could not be determined as each scale consisted of two items only. Obedience to authorities was measured using the two-item short scale of the ALLBUS 2012 Questionnaire (Diekmann et al., 2012). Trait anxiety was assessed using the 12-item neuroticism scale of the German NEO-Five-Factor Inventory (NEO-FFI; Borkenau and Ostendorf, 1993) (Cronbach's $\alpha=.89$ ) and self-esteem with the single-item self-esteem short scale (Robins et al., 2001).

\subsection{Statistical analyses}

Assessed personality traits covaried systematically due to conceptual overlaps. Thus, we extracted higher-order personality domains with an exploratory factor analysis (EFA). Data covariance was adequate for conducting a meaningful EFA (Kaiser-MeyerOlkin measure of sampling adequacy $=.770$; Bartletts's Sphericity test $\left.\chi^{2}(136)=5373.08, p<.001\right)$. A principal component analysis was conducted to max- 
imize extracted variance. Factors with Eigenvalues $\lambda$ $\geq 1$ were extracted and obliquely Promax-rotated $(\kappa=$ 4, with Kaiser normalization).

Associations between personality factors and participants' responses to the moral scenarios were calculated using bivariate nonparametric Kendall's $\tau$ rank correlations. Correlations between measures repeatedly collected across the three scenarios (e.g. assigned imprisonment, moral emotions, moral appropriateness rating) were calculated as repeated measures correlations (using the $\mathrm{R}$ package rmcorr, Bakdash and Marusich, 2016).

Two series of repeated measurement analyses of variances (rmANOVA) were conducted (using the $\mathrm{R}$ package lme4, Bates et al., 2015; with lmerTest, Kuznetsova et al., 2016). First, we compared the scenarios architect vs. footbridge to investigate potential mitigating effects of the utilitarian motive for killing. Second, we compared the scenarios footbridge vs. lifeboat to investigate potentially mitigating effects of the inevitability of harm. All rmANOVAs included the respective scenarios as withinsubject factor, personality domains as betweensubject factors, and all scenario $\times$ personality domain interactions. Each dependent variable-i.e., imposed imprisonment, intensity of negative emotions, intensity of understanding emotions, and perceived moral appropriateness - was investigated in separate analyses. Thus, $p$-values were Bonferroni-corrected for the number of calculated analyses $\left(\alpha_{\text {crit }}<0.00625\right)$.

\section{Results}

\subsection{Exploratory factor analysis}

The EFA assembled the 17 personality trait facets under five superior personality factors, representing $63 \%$ of the trait facets' variance (Table 1). The first personality factor (PF1) spans a continuum from altruism, faith in intuition and the other-oriented empathic traits fantasy, empathic concern, and perspective taking to victim injustice sensitivity and the psychopathy trait callous affect. The second factor (PF2) is characterized by increased neuroticism (i.e., trait anxiety) and personal distress with decreased self-esteem. The third factor (PF3) consists of increased trait psychopathy, with simultaneously lower altruism and increased justice sensitivity from the perpetrator's perspective. The fourth factor (PF4) represents general justice sensitivity across all perspectives (i.e., perpetrators, victims, observers, beneficiaries). The fifth factor (PF5) combines marked FI and little motivation for critical, analytical thinking (i.e., low NFC) with increased authority obedience and greater justice sensitivity from the victim's perspective. PF1, PF3, and PF4 were moderately correlated.

Insert Table 1 about here

\subsection{Descriptive statistics and correlations}

Table 2 presents descriptive statistics and corre- lations of the outcome variables of the moral experiment. Bivariate correlations between personality domains and the outcome variables of the three moral scenarios are displayed in Table 3. Across the three scenarios architect, footbridge, and lifeboat, there was a decrease in punishment and negative emotions, while comprehensive emotions and moral appropriateness increased. Participants reported the greatest difficulties to decide an appropriate level of punishment in the footbridge scenario. A detailed analysis (see Supplementary Analyses) revealed that decision difficulty was a reverse parabolic function of the moral emotion conflict (Supplementary Figure 1). Unsurprisingly, participants found it easier to judge a protagonist's behavior when either negative or positive emotions clearly dominated. Contrariwise, when both emotional tendencies were equally strong, decisions on appropriateness were harder to make.

---------- Insert Table 2 about here ----------

\subsection{Influence of personality and the reasons for killing}

Table 4 summarizes the results of the rmANOVA series comparing selfish (architect) and utilitarian killing (footbridge). Independent of personality differences, selfish killing was punished considerably harsher. On average, perpetrators in the architect dilemma were given a prison sentence that was about 19 years longer compared to the sentence for the perpetrator in the footbridge scenario. Participants felt stronger negative emotions and were less understanding of the perpetrator. Furthermore, they considered selfish killing less morally appropriate than utilitarian killing.

Personality domains (PF1-PF5) showed varying associations with emotional responses and punishment tendencies. The interplay of scenario and personality is displayed in Figure 1.

Participants with more marked PF1 characteristics (other-oriented empathy, altruism, faith in intuition, low callous affect) felt more intense negative emotions in response to both killing scenarios, but particularly in response to selfish killing (architect), than participants with weaker PF1 characteristics (Figure 1b). They also considered utilitarian killing (footbridge) less morally appropriate, while their appropriateness rating of selfish killing did not change (Figure 1d).

Increased PF2 characteristics (anxiety, personal distress, low self-esteem) were associated with slightly more negative emotions.

PF3 characteristics (trait psychopathy, low perpetrator justice sensitivity) were linked to more severe punishments in both scenarios (Figure 1e). However, participants with more pronounced PF3 reported more understanding emotions for the selfish killing in the architect dilemma (Figure 1g) compared to participants with reduced PF3 features. They also rated both killings as more morally appropriate, in particular the utilitarian killing (footbridge). (Fig- 
ure $1 \mathrm{~h})$.

There were no significant main or interaction effects for PF4 (other-oriented justice sensitivity).

Participants with higher levels of PF5 characteristics (FI, victim justice sensitivity, obedience to authorities, and low NFC) punished both killings more severely. In particular, the utilitarian killing in the footbridge scenario received harsher punishment (Figure 1i). Participants with marked PF5 features also reported more intensive negative emotions and, correspondingly, less understanding emotions towards the utilitarian perpetrator compared to subjects with lower PF5 levels (Figure 1j and 1k).

\subsection{Influence of personality and inevitability of harm}

Table 5 summarizes the results of the rmANOVA series comparing utilitarian killings where harming the victims was avoidable (footbridge) or inevitable (lifeboat). In general, utilitarian killings with avoidable harm were punished more severely. On average, perpetrators in the footbridge scenario received prison sentences that were 1.6 years longer compared to the sentences for the perpetrator of the lifeboat dilemma. Consistently, participants felt stronger negative emotions and were less understanding of the perpetrator in the footbridge dilemma and rated the avoidable sacrifices in this scenario as less morally appropriate than the inevitable deaths in the lifeboat dilemma.

Again, personality domains differentially affected emotions and punishments as displayed in Figure 2. Participants with stronger PF1 characteristics (other-oriented empathy, altruism, faith in intuition, low callous affect) reported more intensive negative emotions towards the perpetrators in both scenarios (Figure 2b). In addition, they assessed the killings in both scenarios as less morally appropriate compared to participants with reduced PF1 features (Figure 2d).

In contrast, there were no significant main or interaction effects of PF2 (anxiety, personal distress, low self-esteem).

More pronounced PF3 characteristics (trait psychopathy, low perpetrator justice sensitivity) resulted in harsher punishments in both scenarios (Figure 2e). However, participants with higher PF3 levels also rated the killings both in the footbridge and the lifeboat scenario as more morally appropriate compared to subjects with lower factor scores in PF3 (Figure $2 h)$.

There were again no significant main or interaction effects of PF4 (other-oriented justice sensitivity).

Participants with more marked PF5 characteristics (FI, victim justice sensitivity, obedience to authorities, and low NFC) assigned slightly more severe punishments in both scenarios compared to participants with lower PF5 levels. In particular, the avoidable sacrifice in the footbridge scenario was more severely punished by participants with higher PF5 factor scores (Figure 2i). Consistently, they felt stronger negative emotions in both conditions, espe- cially in the case of the avoidable sacrifice (Figure $2 \mathrm{j}$ ). Still, they felt less understanding emotions in both scenarios, but particularly in the case of avoidable victims (Figure $2 \mathrm{k}$ ).

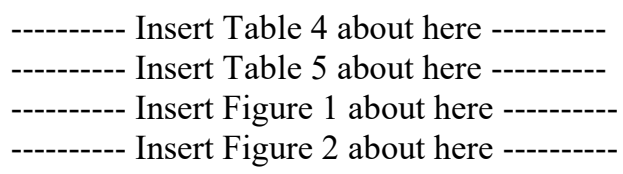

\section{Discussion}

This study investigated the influence of morality-associated personality characteristics on third parties' judgment and punishment of homicides. First, we investigated individual differences in endorsing a utilitarian motive to kill as a mitigating factor. To this effect, we compared self-interested straight up murder (architect scenario) with a "utilitarian" killing motivated by the aim to protect a larger number of individuals from death (footbridge scenario). In general, observers evaluated utilitarian motives as a mitigating factor and assigned milder punishments. Correspondingly, observers rated utilitarian killings as morally more appropriate and perceived towards the perpetrator less negative and more understanding emotions.

Second, we examined individual differences in regarding the inevitability of victims' death as a mitigating factor. To this end, we compared killings where harm was avoidable (footbridge scenario) or inevitable (lifeboat scenario). As previously reported (cf. Moore et al., 2008), observers punished killings less severely when the victims' deaths were inevitable. Accordingly, this type of killing was rated as morally more appropriate and accompanied by less negative and more understanding emotions. However, these general patterns were substantially influenced by observers' personality.

\subsection{Other-oriented empathy and altruism}

How highly empathic/altruistic persons think and feel when judging killings in dilemma situations and which punishments they consider appropriate was previously not investigated. Empathic individuals develop a strong emotional discomfort by being emotionally involved with the fate of threatened individuals and imagining harmful acts during moral decision making (Batson et al., 1995; Miller et al., 2014). In line with this, highly empathic/altruistic observers reported more intense negative emotions towards the perpetrators in all three scenarios. Thus, empathy/altruism led to more emotional aversion towards homicides in general, with the strongest increase of negative emotions in the architect scenario.

In contrast, empathy/altruism did not account for differences in understanding emotions towards perpetrators. High empathic/altruistic observers indicated no increased feelings of pity or compassion with the perpetrators in the footbridge or lifeboat scenarios, although these protagonists were in a des- 
perate situation themselves. Considering that otheroriented empathy/altruism was linked to higher aversive emotions, but not to understanding emotions towards perpetrators indicates that third parties' empathic tendencies appear to be focused on the victims' fate.

In first-person-perspective moral decision making, higher other-oriented empathy was linked to more unpleasant feelings as well as less utilitarian and more deontic choices (Choe and Min, 2011; Conway and Gawronski, 2013; Gleichgerrcht and Young, 2013; McIlwain et al., 2012; Patil and Silani, 2014). In line with this, we found highly empathic/altruistic observers judging deontic rule transgressions more morally inappropriate. This indicates that empathic/altruistic observers considered the utilitarian motive less mitigating when making cognitive judgments on the appropriateness of actions. However, there were no differences in the resulting punishment judgments.

\subsection{Empathic distress and trait anxiety}

Empathic distress and trait anxiety (i.e. neuroticism) characterize individuals who are prone to feel fear, discomfort or shame when confronted with others' suffering and report low self-esteem (Batson et al., 1987; Davis, 1983). To end this aversive emotional state, highly distressed/anxious individuals tend to help quickly or-even more often-to evade the situation resulting in less prosocial behavior (Haidt, 2003). Our own results show a negative correlation between empathic distress/anxiety with otheroriented empathy/altruism. In the first-party perspective, empathic distress was in fact linked to less utilitarian moral choices (Sarlo et al., 2014). As an explanation, the authors speculated whether highly empathically distressed individuals quickly choose deontic solutions in order to end their negative feelings caused by imagining the suffering of others when intensely deliberating the situational setting (Sarlo et al., 2014). In our study, however, there were no associations of empathic distress/anxiety with observers' cognitive, emotional or punitive reactions. The only exception was a marginal increase of negative emotions in the architect and footbridge scenarios. It could be speculated whether this was the result of an increased unspecific negative affect due to imagining human suffering (Batson et al., 1987). Future research could assess self-oriented emotions (i.e., anxiety, discomfort, shame or helplessness) to clarify the emotional state of highly empathic distressed/anxious individuals when judging homicides.

\subsection{Trait psychopathy}

Previous studies using first-person perspectives showed consistently that individuals with psychopathic tendencies prefer utilitarian solutions in moral dilemmas (Bartels and Pizarro, 2011; Djeriouat and Trémolière, 2014; Gao and Tang, 2013; Glenn et al., 2010; Kahane et al., 2015; Koenigs et al., 2012; Langdon and Mackenzie, 2012; Patil, 2015; SearaCardoso et al., 2013; Tassy et al., 2013a). In our study on third-party perspectives, however, observers with higher trait-psychopathy scores judged all killings more morally appropriate, irrespective of utilitarian motives. Moreover, they considered killing of avoidable victims more morally appropriate than observers with lower psychopathy scores. In addition, they showed more understanding towards the selfish murderer in the architect scenario. This indicates that individuals with higher trait-psychopathy scores did not selectively excuse utilitarian killings, but instead considered killing itself, i.e. violating a deontic rule, less morally condemnable. Thus, observers with more marked psychopathic tendencies were less morally troubled by killings.

In previous studies, not respecting deontic rules was accompanied by reduced aversive emotional responses to witnessing or inflicting harm (Patil, 2015), which might be due to reduced empathy for victims or individuals in need (Aharoni et al., 2011; Glenn et al., 2009a, 2009b; McIlwain et al., 2012; Seara-Cardoso et al., 2012, 2013). The absence of empathic concern for others was linked to less moralreconstituting anger in observers when witnessing unfair treatment of others (Batson et al., 2007). In our study, however, no psychopathy-related differences were evident in negative emotions towards perpetrators.

Paradox, however, observers with high trait psychopathy (and low perpetrator injustice sensitivity) imposed harsher punishments in all conditions. Taking the position of a judge could serve the psychopathic need of a grandiose self and allows them to live out their propensity to dominate others (Hare and Neumann, 2009). These tendencies might have manifested themselves in harsher punishments despite a more understanding attitude towards perpetrators' actions. Moreover, psychopaths were reported to be quite able to cognitively distinguish right from wrong, although they show less of the usual moral emotions and care less about deontic norms when acting (Glenn et al., 2009a). Importantly, the deontic principle to avoid unnecessary harm also applies to perpetrators, i.e. they should not be punished unnecessarily harshly. Thus, the association between traitpsychopathy scores and harsher punishment might again reflect a general disrespect for deontic rules, including the protection of perpetrators from unnecessary suffering. Nevertheless, it should be kept in mind that our study did not investigate clinical psychopathic individuals but trait psychopathy in a community sample.

\subsection{Other-oriented justice sensitivity}

In previous studies, individuals with higher other-oriented justice sensitivity rated immoral behavior in moral dilemmas as less permissible and showed more empathic concern and perspective taking as well as lower trait psychopathy (Decety and Yoder, 2015). In this study, exploratory factor analysis indicated a domain mainly characterized by otheroriented justice sensitivity from the observer and beneficiary perspectives. Conversely, victim and 
perpetrator injustice sensitivity were only partially associated. As previously shown (Strobel et al., 2017), victim sensitivity was further associated with a tendency to intuitive and authoritarian thinking. Further in line with previous findings (Decety and Yoder, 2015), lower perpetrator justice sensitivity was related to increased trait psychopathy. Otheroriented justice sensitivity was positively associated with negative emotions towards the perpetrator across all scenarios, although the effect did not remain significant when controlling for other moralrelated personality domains. This partially corresponds to a previous study reporting more anger and more severe punishments in third-party participants with higher other-oriented justice sensitivity (Lotz et al., 2011a).

\subsection{Need for cognition and intuitive/authority- obedient thinking}

Highly intuitive/authority-obedient thinking observers reported significantly more negative and less understanding emotions for utilitarian killings (i.e., killing to reduce the total net harm) than observers with high NFC scores. Moreover, their emotional reactions differed less between utilitarian killings (footbridge) and selfish murder (architect). In contrast, third parties with high NFC scores were emotionally sensitive to perpetrators' utilitarian motives, i.e., they reported considerably less negative and more comprehensive emotions towards utilitarian perpetrators in lifeboat and footbridge than towards the selfish killing by the architect. Consistently, third parties with high NFC scores punished perpetrators with utilitarian killings motives considerably milder than highly intuitive/authority-obedient thinking observers.

These results correspond with moral decisionmaking from the first-party perspective. Participants with greater FI made more deontic and less utilitarian judgments (Bartels, 2008; Petrocelli and Dowd, 2009), whereas participants prone to deliberative reasoning made more utilitarian judgments (Conway and Gawronski, 2013; Paxton et al., 2012; Paxton and Greene, 2010). As explanations, individual differences in cognitive motivation and/or ability to encode and analyze the overall situation have been suggested. Conway and Gawronski (2013) demonstrated that utilitarian judgment tendencies are selectively impaired due to cognitive load, while deontic tendencies remained unchanged (but see Tinghög et al., 2016). Sargent (2004) theorized that high-NFC individuals are more able and/or willing to mobilize cognitive efforts for deliberating perpetrators' motives, reasons, and situational constraints when judging behavior. In turn, they rely less on situationally invariant deontic judgment templates and thus, less support harsh punitive responses to crime. Conversely, individuals with authority-obedient mindsets were found to less likely examine or integrate more than one perspective on a (moral) problem, especially concerning questions on existential issues such as life and death (Hunsberger et al., 1994). Rather they "solved" moral problems through a quickly and situationally invariant application of deontic moral rules (e.g., Antonenko Young et al., 2013; Conway and Gawronski, 2013; Hunsberger et al., 1994; Kimhi, 2014; Szekely et al., 2015).

However, our results do not generally support these notions. In fact, intuitive/authority-obedient thinking observers mitigated punishment for perpetrators with utilitarian motives, although to a much lesser extent than high-NFC observers. Moreover, they reported more understanding and less negative emotions in reaction to utilitarian killings with inevitable (lifeboat) compared to avoidable harm (footbridge). Thus, although being less sensitive for the utilitarian motives in general, highly intuitive/authority-obedient thinking observers considered the inevitability of harm as an important mitigating factor. Hence, intuitive/authority-obedient thinking observers appear to perceive situational differences indeed very precisely. However, they apparently give greater weight to the deontic principle of preventing avoidable harm. In contrast, high NFC observers generally pay attention to reducing the total damage for all, with the evitability of harm being of lesser importance for their judgement.

Further support for this notion derives from our observation that moral appropriateness judgements did not differ between highly intuitive/authorityobedient thinking and high-NFC observers across all scenarios. Thus, personality-related differences in preferring moral principles did not lead to differences in the cognitive analysis or evaluation of scenarios, but primarily manifested in observers' emotional and punitive reactions. Considering the importance of emotional reactions, previous studies demonstrated that authority-obedient individuals tend to experience pronounced aggressive feelings and to impose harsher sanctions on violators of deontic norms in general (Lerner et al., 1998). However, our results do not fully support this conclusion. Intuitive/authorityobedient thinking observers did not punish selfish murder (architect) more harshly than high-NFC observers. Thus, intuitive/authority-obedient thinking did not result in more severe retaliation for deontic rule violations in general.

Taken together, third parties perceive the variety of motives and situational constraints of perpetrators that chose to kill. However, the thinking style of observers strongly influenced how they emotionally evaluated the motives and constraints of killings. Intuitive/authority-obedient thinking observers valued utilitarian killing motives to a lesser extent as a mitigating factor and instead focused on the prevention of evitable harm when judging killings. Conversely, third parties with high NFC scores valued the utilitarian motive of perpetrators to minimize the total harm as a strong mitigating constraint when judging killings, but focused to a lesser extent on the fact whether the victims' harm was evitable in principle. 


\subsection{Strengths, limitations, and future research}

Among the strengths of this study is a large sample size which allowed us to detect even small effects. Assessing emotional, cognitive, and punitive responses allowed investigating comprehensively on which levels morality-associated personality traits influence third parties' judgment of homicides. Our inclusive approach of exploring influences of several moral-associated personality facets in one study provided a broad overview of the possible effects of interindividual differences and permits deducting specific hypotheses for future studies. Constraints on generality may result from the fact that the present sample consisted mainly of young, Central/Western European, atheist or Christian academics. Sanctioning behavior could differ in populations with different educational, moral, religious or cultural background. Moreover, we asked nonjudicial participants for their intuitive emotional, cognitive and punitive reactions. Their decision might not be comparable to the rationally deliberated verdict of a professional judge. However, judging real-life crimes is not always delegated to professional judges. Depending on the legal system, a jury consisting of lay persons might be in charge of deciding whether alleged perpetrators are guilty and how they should be punished. Thus, findings on moral judgements by lay persons have relevance in real-life. Furthermore, there is evidence that German lay persons' judgments on violent crimes did not considerably differ regardless whether they were instructed to judge intuitively or elaborately, rationally reasoned (Löbmann et al., 2007).

Beside its strengths, this study has limitations. Data collection was conducted online, presenting an innately less controllable experimental setting. While moral dilemmas have been widely used in research, their usefulness for predicting moral behavior in reallife situations is debatable. To avoid carry-over effects (Wiegmann and Waldmann, 2014), the compared moral scenarios effects were embedded in a randomly chosen series of filler scenarios. In our study, we examined two clearly defined condition differences of killing behavior. Hence, future studies are necessary to create additional scenarios by modifying situational and motivational features and investigate their interplay with third parties' personality.

\section{Conclusions}

In line with previous studies on moral decision making, utilitarian motives were considered mitigating and resulted in less severe punishment by thirdparty observers. Similarly, killing people who would have died anyway was punished less severely than killing people who might have survived. Punitive reactions were accompanied by cognitive appraisal of the appropriateness of perpetrators' actions as well as negative/hostile and understanding emotions towards transgressors. No influence on punishment was found for the personality factors (a) other-oriented empathy/altruism, (b) empathic distress/trait anxiety, and (c) other-oriented justice sensitivity. Conversely, trait psychopathic tendencies and differences in thinking styles accounted for significant differences in observers' emotional, cognitive, and punitive reactions. Observers with marked trait psychopathy did not selectively condone utilitarian killings, but instead judged killing in general-as a deontic rule transgression-more morally permissible. However, they also punished perpetrators more harshly, which could reflect their generally lower inclination to endorse the deontic principle of protecting individuals from unnecessary harm-irrespective of being victim or perpetrator. Observers with higher NFC scores valued utilitarian motives to kill as a strong mitigating factor, but less consideration was given to whether the damage to the victim was avoidable. In contrast, observers characterized by intuitive/authorityobedient thinking attached particular importance to the principle avoidability of damage and considered utilitarian motives of killers to a lesser extent as mitigating when punishing.

Taken together, this study shows that personality differences influence third-party judgments and punishments of homicides to a practically relevant magnitude. As personality differences account for behavioral differences already in strong situations such as homicides, even stronger personality-related differences in altruistic behavior and moral decision making are to be expected in weaker, less clear-cut situations (e.g. Carlo et al., 1991). In various real-life contexts (Morrison, 2014), investigating the role of personality might help to explain why people remain silent and others intervene when observing moral misbehavior.

\section{Author contribution}

AB, DA, and AS developed the study concept. $\mathrm{AB}$ conducted the study setup and data collection and performed the statistical data analysis. AB and DA drafted the paper. All authors contributed to the interpretation of data, critically revised the manuscript, and approved the final version of the paper for submission.

\section{Conflict of interest}

The authors have no conflict of interest to declare.

\section{$8 \quad$ Funding}

None.

\section{Data availability statement}

Data, code, and supplementary materials may be retrieved from https://osf.io/3wsxh.

\section{References}

Aharoni, E., Antonenko, O., and Kiehl, K. A. (2011). Disparities in the moral intuitions of criminal offenders: The role of psychopathy. J. Res. Per- 
sonal. $45,322-327$.

doi:10.1016/j.jrp.2011.02.005.

Antonenko Young, O., Willer, R., and Keltner, D. (2013). "Thou shalt not kill": Religious fundamentalism, conservatism, and rule-based moral processing. Psychol. Relig. Spiritual. 5, 110115. doi:10.1037/a0032262.

Bakdash, J. Z., and Marusich, L. R. (2016). rmcorr: Repeated measures correlation. Available at: https://cran.rproject.org/web/packages/rmcorr/rmcorr.pdf [Accessed April 26, 2017].

Bartels, D. M. (2008). Principled moral sentiment and the flexibility of moral judgment and decision making. Cognition 108, 381-417. doi:10.1016/j.cognition.2008.03.001.

Bartels, D. M., and Pizarro, D. A. (2011). The mismeasure of morals: Antisocial personality traits predict utilitarian responses to moral dilemmas. Cognition 121, 154-161. doi:10.1016/j.cognition.2011.05.010.

Bates, D., Mächler, M., Bolker, B., and Walker, S. (2015). Fitting linear mixed-effects models using lme4. J. Stat. Softw. 67, 1-48. doi:10.18637/jss.v067.i01.

Batson, C. D., Fultz, J., and Schoenrade, P. A. (1987). Distress and empathy: Two qualitatively distinct vicarious emotions with different motivational consequences. J. Pers. 55, 19-39. doi:10.1111/j.1467-6494.1987.tb00426.x.

Batson, C. D., Kennedy, C. L., Nord, L.-A., Stocks, E. L., Fleming, D. A., Marzette, C. M., et al. (2007). Anger at unfairness: is it moral outrage? Eur. J. Soc. Psychol. 37, 1272-1285. doi:10.1002/ejsp.434.

Batson, C. D., Klein, T. R., Highberger, L., and Shaw, L. L. (1995). Immorality from empathyinduced altruism: When compassion and justice conflict. J. Pers. Soc. Psychol. 68, 1042.

Batson, C. D., and Powell, A. A. (2003). Altruism and prosocial behavior. Handb. Psychol., 463484.

Baumert, A., and Schmitt, M. (2016). "Justice sensitivity," in Handbook of Social Justice Theory and Research, eds. C. Sabbagh and M. Schmitt (New York, NY: Springer New York), 161180. Available at: http://link.springer.com/10.1007/978-1-49393216-0_9 [Accessed December 5, 2016].

Beierlein, C., Baumert, A., Schmitt, M., Kemper, C. J., and Rammstedt, B. (2013). Vier Kurzskalen zur Messung des Persönlichkeitsmerkmals „Sensibilität für Ungerechtigkeit“. Methoden Daten Anal. 7, 279-310. doi:10.12758/mda.2013.01.

Bendor, J., and Swistak, P. (2001). The evolution of norms. Am. J. Sociol. 106, 1493-1545. doi:10.1086/321298.

Blair, R. J. R., White, S. F., Meffert, H., and Hwang, S. (2013). Emotional learning and the development of differential moralities: Implications from research on psychopathy. Ann. N. Y. Acad. Sci. 1299, 36-41. doi:10.1111/nyas.12169.

Borkenau, P., and Ostendorf, F. (1993). NEO-FünfFaktoren Inventar (NEO-FFI): nach Costa und $M c C r a e$. Göttingen: Hogrefe.

Boyd, R., Gintis, H., Bowles, S., and Richerson, P. J. (2003). The evolution of altruistic punishment. Proc. Natl. Acad. Sci. 100, 3531-3535. doi:10.1073/pnas.0630443100.

Carlo, G., Eisenberg, N., Troyer, D., Switzer, G., and Speer, A. L. (1991). The altruistic personality: In what contexts is it apparent? J. Pers. Soc. Psychol. 61, 450-458. doi:10.1037/00223514.61.3.450.

Carlsmith, K. M., Darley, J. M., and Robinson, P. H. (2002). Why do we punish?: Deterrence and just deserts as motives for punishment. J. Pers. Soc. Psychol. 83, 284-299. doi:10.1037//00223514.83.2.284.

Choe, S. Y., and Min, K.-H. (2011). Who makes utilitarian judgments? The influences of emotions on utilitarian judgments. Judgm. Decis. Mak. 6, 580-592.

Christensen, J. F., Flexas, A., Calabrese, M., Gut, N. K., and Gomila, A. (2014). Moral judgment reloaded: a moral dilemma validation study. Front. Psychol. 5. doi:10.3389/fpsyg.2014.00607.

Christensen, J. F., and Gomila, A. (2012). Moral dilemmas in cognitive neuroscience of moral decision-making: A principled review. Neurosci. Biobehav. Rev. 36, 1249-1264. doi:10.1016/j.neubiorev.2012.02.008.

Cima, M., Tonnaer, F., and Hauser, M. D. (2010). Psychopaths know right from wrong but don't care. Soc. Cogn. Affect. Neurosci. 5, 59-67. doi:10.1093/scan/nsp051.

Condon, P., and DeSteno, D. (2011). Compassion for one reduces punishment for another. J. Exp. Soc. Psychol. 47, 698-701. doi:10.1016/j.jesp.2010.11.016.

Conway, P., and Gawronski, B. (2013). Deontological and utilitarian inclinations in moral decision making: A process dissociation approach. $J$. Pers. Soc. Psychol. 104, 216-235. doi:10.1037/a0031021.

Cushman, F. (2008). Crime and punishment: Distinguishing the roles of causal and intentional analyses in moral judgment. Cognition 108, 353-380. doi:10.1016/j.cognition.2008.03.006.

Cushman, F., Gray, K., Gaffey, A., and Mendes, W. B. (2012). Simulating murder: the aversion to harmful action. Emotion 12, 2-7. doi:10.1037/a0025071.

Cushman, F., Young, L., and Hauser, M. (2006). The role of conscious reasoning and intuition in moral judgment testing three principles of harm. Psychol. Sci. 17, 1082-1089. doi:10.1111/j.1467-9280.2006.01834.x.

Davis, M. H. (1983). Measuring individual differences in empathy: Evidence for a multidimen- 
sional approach. J. Pers. Soc. Psychol. 44, 113 126. doi:10.1037/0022-3514.44.1.113.

Decety, J., and Yoder, K. J. (2015). Empathy and motivation for justice: Cognitive empathy and concern, but not emotional empathy, predict sensitivity to injustice for others. Soc. Neurosci. 11, 1-14. doi:10.1080/17470919.2015.1029593.

DeScioli, P., Bruening, R., and Kurzban, R. (2011). The omission effect in moral cognition: toward a functional explanation. Evol. Hum. Behav. 32, 204-215. doi:10.1016/j.evolhumbehav.2011.01.003.

DeScioli, P., and Kurzban, R. (2009). Mysteries of morality. Cognition 112, 281-299. doi:10.1016/j.cognition.2009.05.008.

Diekmann, A., Fetchenhauer, D., Kühnel, S., Liebig, S., Schmitt-Beck, R., Trappe, H., et al. (2012). ALLBUS Allgemeine Bevölkerungsumfrage der Sozialwissenschaften 2012. GESIS - Leibniz Inst. Soc. Sci. ZA4614. doi:10.4232/1.11595.

Djeriouat, H., and Trémolière, B. (2014). The dark triad of personality and utilitarian moral judgment: The mediating role of honesty/humility and harm/care. Personal. Individ. Differ. 67, 11-16. doi:10.1016/j.paid.2013.12.026.

Epstein, S., Pacini, R., Denes-Raj, V., and Heier, H. (1996). Individual differences in intuitiveexperiential and analytical-rational thinking styles. J. Pers. Soc. Psychol. 71, 390.

Fehr, E., and Fischbacher, U. (2003). The nature of human altruism. Nature 425, 785-791. doi:10.1038/nature02043.

Fehr, E., and Fischbacher, U. (2004). Third-party punishment and social norms. Available at: http://www.sciencedirect.com/science/article/pii /S1090513804000054 [Accessed November 7, 2015].

Fehr, E., and Gächter, S. (2002). Altruistic punishment in humans. Nature 415, 137-140. doi:10.1038/415137a.

Fetchenhauer, D., and Huang, X. (2004). Justice sensitivity and distributive decisions in experimental games. Personal. Individ. Differ. 36, 1015-1029. doi:10.1016/S01918869(03)00197-1.

Fiske, A. P., and Tetlock, P. E. (1997). Taboo tradeoffs: Reactions to transactions that transgress the spheres of justice. Polit. Psychol. 18, 255297. doi:10.1111/0162-895X.00058.

Foot, P. (1967). The problem of abortion and the doctrine of double effect. Oxf. Rev. 5, 5-15.

Gao, Y., and Tang, S. (2013). Psychopathic personality and utilitarian moral judgment in college students. J. Crim. Justice 41, 342-349. doi:10.1016/j.jcrimjus.2013.06.012.

Gleichgerrcht, E., and Young, L. (2013). Low levels of empathic concern predict utilitarian moral judgment. PloS One 8, e60418. doi:10.1371/journal.pone.0060418.

Glenn, A. L., Iyer, R., Graham, J., Koleva, S., and Haidt, J. (2009a). Are all types of morality compromised in psychopathy? J. Personal. Disord. 23, 384-398.

Glenn, A. L., Koleva, S., Iyer, R., Graham, J., and Ditto, P. H. (2010). Moral identity in psychopathy. Judgm. Decis. Mak. 5, 497-505.

Glenn, A. L., Raine, A., Schug, R. A., Young, L., and Hauser, M. (2009b). Increased DLPFC activity during moral decision-making in psychopathy. Mol. Psychiatry 14, 909-911. doi:10.1038/mp.2009.76.

Graham, J., Nosek, B. A., Haidt, J., Iyer, R., Koleva, S., and Ditto, P. H. (2011). Mapping the moral domain. J. Pers. Soc. Psychol. 101, 366-385. doi: $10.1037 / \mathrm{a} 0021847$.

Greene, J. D., Cushman, F. A., Stewart, L. E., Lowenberg, K., Nystrom, L. E., and Cohen, J. D. (2009). Pushing moral buttons: The interaction between personal force and intention in moral judgment. Cognition 111, 364-371. doi:10.1016/j.cognition.2009.02.001.

Greene, J. D., Morelli, S. A., Lowenberg, K., Nystrom, L. E., and Cohen, J. D. (2008). Cognitive load selectively interferes with utilitarian moral judgment. Cognition 107, 1144-1154. doi:10.1016/j.cognition.2007.11.004.

Greene, J. D., Nystrom, L. E., Engell, A. D., Darley, J. M., and Cohen, J. D. (2004). The neural bases of cognitive conflict and control in moral judgment. Neuron 44, 389-400. doi:10.1016/j.neuron.2004.09.027.

Greene, J. D., Sommerville, R. B., Nystrom, L. E., Darley, J. M., and Cohen, J. D. (2001). An fMRI investigation of emotional engagement in moral judgment. Science 293, 2105-2108. doi:10.1126/science. 1062872 .

Haidt, J. (2003). "The moral emotions," in Handbook of Affective Sciences, eds.R. J. Davidson, K. R. Scherer, and H. H. Goldsmith (Oxford: Oxford University Press), 852-870.

Hare, R. D., and Neumann, C. S. (2009). Psychopathy: Assessment and forensic implications. Can. J. Psychiatry 54, 791-802. doi:10.1177/070674370905401202.

Hauser, M., Cushman, F., Young, L., Kang-Xing Jin, R., and Mikhail, J. (2007). A dissociation between moral judgments and justifications. Mind Lang. 22, 1-21. doi:10.1111/j.14680017.2006.00297.x.

Hopfensitz, A., and Reuben, E. (2009). The importance of emotions for the effectiveness of social punishment. Econ. J. 119, 1534-1559. doi:10.1111/j.1468-0297.2009.02288.x.

Horne, Z., and Powell, D. (2016). How large is the role of emotion in judgments of moral dilemmas? PLOS ONE 11, e0154780. doi:10.1371/journal.pone.0154780.

Hunsberger, B., Pratt, M., and Pancer, S. M. (1994). Religious fundamentalism and integrative complexity of thought: A relationship for existential content only? J. Sci. Study Relig. 33, 335. doi:10.2307/1386493. 
Kahane, G., Everett, J. A. C., Earp, B. D., Farias, M., and Savulescu, J. (2015). 'Utilitarian' judgments in sacrificial moral dilemmas do not reflect impartial concern for the greater good. Cognition 134, 193-209. doi:10.1016/j.cognition.2014.10.005.

Keller, J., Bohner, G., and Erb, H.-P. (2000). Intuitive und heuristische Urteilsbildung - verschiedene Prozesse? Präsentation einer deutschen Fassung des "Rational-Experiential Inventory" sowie neuer Selbstberichtskalen zur Heuristiknutzung. Z. Für Sozialpsychologie 31, 87-101. doi:10.1024//0044-3514.31.2.87.

Kimhi, S. (2014). Moral dilemmas in the war against terrorism: Proportionality principle, religiosity, political attitudes and authoritarian personality. in (Montreal, Canada). Available at: http://paperroom.ipsa.org/papers/paper_30912.p df [Accessed May 12, 2015].

Kinnunen, S. P., and Windmann, S. (2013). Dualprocessing altruism. Front. Psychol. 4. doi:10.3389/fpsyg.2013.00193.

Koenigs, M., Kruepke, M., Zeier, J., and Newman, J. P. (2012). Utilitarian moral judgment in psychopathy. Soc. Cogn. Affect. Neurosci. 7, 708714. doi:10.1093/scan/nsr048.

Koenigs, M., Young, L., Adolphs, R., Tranel, D., Cushman, F., Hauser, M., et al. (2007). Damage to the prefrontal cortex increases utilitarian moral judgements. Nature 446, 908-911. doi:10.1038/nature05631.

Kuznetsova, A., Brockhoff, P. B., and Christensen, R. H. B. (2016). lmerTest: Tests in linear mixed effects models. Available at: https://CRAN.Rproject.org/package $=$ lmerTest.

Langdon, R., and Mackenzie, C. (2012). "Moral reasoning and psychopathic tendencies in the general community," in Emotions, imagination, and moral reasoning: Macquarie monographs in cognitive science, eds. R. Langdon and C. Mackenzie (New York, NY: Psychology Press), 91-118.

Lerner, J. S., Goldberg, J. H., and Tetlock, P. E. (1998). Sober second thought: The effects of accountability, anger, and authoritarianism on attributions of responsibility. Pers. Soc. Psychol. Bull. 24, 563-574. doi:10.1177/0146167298246001.

LimeSurvey GmbH (2017). LimeSurvey: An open source survey tool. Hamburg, Germany: LimeSurvey GmbH Available at: http://www.limesurvey.org.

Löbmann, R., Suhling, S., and Greve, W. (2007). Emotionale Reaktionen auf Straftaten: eine explorative Studie zu Unterschieden zwischen intuitiven und rationalen Strafurteilen. Kriminalsoziologie Rechtssoziol. 1, 9-19.

Lombrozo, T. (2009). The role of moral commitments in moral judgment. Cogn. Sci. 33, 273 286. doi:10.1111/j.1551-6709.2009.01013.x.

Lotz, S., Baumert, A., Schlösser, T., Gresser, F., and Fetchenhauer, D. (2011a). Individual differ- ences in third-party interventions: How justice sensitivity shapes altruistic punishment. Negot. Confl. Manag. Res. 4, 297-313.

Lotz, S., Okimoto, T. G., Schlösser, T., and Fetchenhauer, D. (2011b). Punitive versus compensatory reactions to injustice: Emotional antecedents to third-party interventions. J. Exp. Soc. Psychol. 47, 477-480. doi:10.1016/j.jesp.2010.10.004.

McCall, C., Steinbeis, N., Ricard, M., and Singer, T. (2014). Compassion meditators show less anger, less punishment, and more compensation of victims in response to fairness violations. Front. Behav. Neurosci. 8. doi:10.3389/fnbeh.2014.00424.

McClaren, N., Adam, S., and Vocino, A. (2009). NFC, moral position, socialisation, and ethical decision-making. in (Monash University, Melbourne: Vic.), 1-9.

McIlwain, D., Evans, J., Caldis, E., Cicchini, F., Aronstan, A., Wright, A., et al. (2012). "Strange moralities: Vicarious emotion and moral emotions in Machiavellian and psychopathic personality styles," in Emotions, imagination, and moral reasoning: Macquarie monographs in cognitive science, eds. R. Langdon and C. Mackenzie (New York, NY: Psychology Press), 119-148.

Mikhail, J. (2007). Universal moral grammar: theory, evidence and the future. Trends Cogn. Sci. 11, 143-152. doi:10.1016/j.tics.2006.12.007.

Miller, R. M., and Cushman, F. (2013). Aversive for me, wrong for you: First-person behavioral aversions underlie the moral condemnation of harm. Soc. Personal. Psychol. Compass 7, 707718. doi:10.1111/spc3.12066.

Miller, R. M., Hannikainen, I. A., and Cushman, F. A. (2014). Bad actions or bad outcomes? Differentiating affective contributions to the moral condemnation of harm. Emotion 14, 573-587. doi:10.1037/a0035361.

Molenmaker, W. E., de Kwaadsteniet, E. W., and van Dijk, E. (2014). On the willingness to costly reward cooperation and punish noncooperation: The moderating role of type of social dilemma. Organ. Behav. Hum. Decis. Process. $125,175-183$. doi:10.1016/j.obhdp.2014.09.005.

Moore, A. B., Clark, B. A., and Kane, M. J. (2008). Who shalt not kill? Individual differences in working memory capacity, executive control, and moral judgment. Psychol. Sci. 19, 549-557. doi:10.1111/j.1467-9280.2008.02122.x.

Morrison, E. W. (2014). Employee voice and silence. Annu. Rev. Organ. Psychol. Organ. Behav. 1, 173-197. doi:10.1146/annurev-orgpsych031413-091328.

Mussel, P., Göritz, A. S., and Hewig, J. (2013). Which choice is the rational one? An investigation of need for cognition in the ultimatum game. J. Res. Personal. 47, 588-591. doi:10.1016/j.jrp.2013.05.007. 
Nadelhoffer, T., and Feltz, A. (2008). The actorobserver bias and moral intuitions: Adding fuel to Sinnott-Armstrong's fire. Neuroethics 1, 133-144. doi:10.1007/s12152-008-9015-7.

Nelissen, R. M., and Zeelenberg, M. (2009). Moral emotions as determinants of third-party punishment: Anger, guilt and the functions of altruistic sanctions. Judgm. Decis. Mak. 4, 543-553.

Ostendorf, F., and Angleitner, A. (2004). NEOPersönlichkeitsinventar nach Costa und McCrae, Revidierte Fassung (NEO-PI-R). Göttingen: Hogrefe.

Patil, I. (2015). Trait psychopathy and utilitarian moral judgement: The mediating role of action aversion. J. Cogn. Psychol. 27, 349-366. doi:10.1080/20445911.2015.1004334.

Patil, I., and Silani, G. (2014). Reduced empathic concern leads to utilitarian moral judgments in trait alexithymia. Front. Psychol. 5. doi:10.3389/fpsyg.2014.00501.

Paulus, C. (2009). Der Saarbrücker Persönlichkeitsfragebogen SPF (IRI) zur Messung von Empathie: Psychometrische Evaluation der deutschen Version des Interpersonal Reactivity Index. Saarbrücken: Universität des Saarlandes Available at: http://psydok.sulb.unisaarland.de/volltexte/2009/2363/ [Accessed May 11, 2015].

Paulus, C. (2014). Personal distress: Das Sorgenkind der Empathiemessung. Saarbrücken: Universität des Saarlandes Available at:

http://psydok.sulb.unisaarland.de/volltexte/2014/5007/ [Accessed May 11, 2015].

Paxton, J. M., and Greene, J. D. (2010). Moral reasoning: Hints and allegations. Top. Cogn. Sci. 2, 511-527. doi:10.1111/j.17568765.2010.01096.x.

Paxton, J. M., Ungar, L., and Greene, J. D. (2012). Reflection and reasoning in moral judgment. Cogn. Sci. 36, 163-177. doi:10.1111/j.15516709.2011.01210.x.

Petrocelli, J. V., and Dowd, K. (2009). Ease of counterfactual thought generation moderates the relationship between need for cognition and punitive responses to crime. Pers. Soc. Psychol. Bull. 35, 1179-1192. doi:10.1177/0146167209337164.

Quinn, W. S. (1989). Actions, intentions, and consequences: The doctrine of double effect. Philos. Public Aff. 18, 334-351. doi:10.2307/2185021.

Robins, R. W., Hendin, H. M., and Trzesniewski, K. H. (2001). Measuring global self-esteem: Construct validation of a single-item measure and the Rosenberg Self-Esteem Scale. Pers. Soc. Psychol. Bull. 27, 151-161. doi:10.1177/0146167201272002.

Rudolph, U., and Tscharaktschiew, N. (2014). An attributional analysis of moral emotions: naïve scientists and everyday judges. Emot. Rev. 6, 344-352. doi:10.1177/1754073914534507.
Sargent, M. J. (2004). Less thought, more punishment: Need for cognition predicts support for punitive responses to crime. Pers. Soc. Psychol. Bull. 30, 1485-1493. doi:10.1177/0146167204264481.

Sarlo, M., Lotto, L., Rumiati, R., and Palomba, D. (2014). If it makes you feel bad, don't do it! Egoistic rather than altruistic empathy modulates neural and behavioral responses in moral dilemmas. Physiol. Behav. 130, 127-134. doi:10.1016/j.physbeh.2014.04.002.

Schaich Borg, J., Kahn, R. E., Sinnott-Armstrong, W., Kurzban, R., Robinson, P. H., and Kiehl, K. A. (2013). Subcomponents of psychopathy have opposing correlations with punishment judgments. J. Pers. Soc. Psychol. 105, 667-687. doi:10.1037/a0033485.

Seara-Cardoso, A., Dolberg, H., Neumann, C., Roiser, J. P., and Viding, E. (2013). Empathy, morality and psychopathic traits in women. Personal. Individ. Differ. 55, 328-333. doi:10.1016/j.paid.2013.03.011.

Seara-Cardoso, A., Neumann, C., Roiser, J., McCrory, E., and Viding, E. (2012). Investigating associations between empathy, morality and psychopathic personality traits in the general population. Personal. Individ. Differ. 52, 67-71. doi:10.1016/j.paid.2011.08.029.

Seip, E. C., Van Dijk, W. W., and Rotteveel, M. (2014). Anger motivates costly punishment of unfair behavior. Motiv. Emot. 38, 578-588. doi:10.1007/s11031-014-9395-4.

Skoe, E. E., Eisenberg, N., and Cumberland, A. (2002). The role of reported emotion in real-life and hypothetical moral dilemmas. Pers. Soc. Psychol. Bull. 28, 962-973. doi:10.1177/014616720202800709.

Stouten, J., De Cremer, D., and van Dijk, E. (2006). Violating equality in social dilemmas: Emotional and retributive reactions as a function of trust, attribution, and honesty. Pers. Soc. Psychol. Bull. 32, 894-906. doi:10.1177/0146167206287538.

Strobel, A., Grass, J., Pohling, R., and Strobel, A. (2017). Need for cognition as a moral capacity. Personal. Individ. Differ. 117, 42-51. doi:10.1016/j.paid.2017.05.023.

Szekely, R. D., Opre, A., and Miu, A. C. (2015). Religiosity enhances emotion and deontological choice in moral dilemmas. Personal. Individ. Differ. 79, 104-109. doi:10.1016/j.paid.2015.01.036.

Tassy, S., Deruelle, C., Mancini, J., Leistedt, S., and Wicker, B. (2013a). High levels of psychopathic traits alters moral choice but not moral judgment. Front. Hum. Neurosci. 7. doi:10.3389/fnhum.2013.00229.

Tassy, S., Oullier, O., Mancini, J., and Wicker, B. (2013b). Discrepancies between judgment and choice of action in moral dilemmas. Front. Psychol. 4, 250. doi:10.3389/fpsyg.2013.00250. 
Tinghög, G., Andersson, D., Bonn, C., Johannesson, M., Kirchler, M., Koppel, L., et al. (2016). Intuition and moral decision-making - The effect of time pressure and cognitive load on moral judgment and altruistic behavior. PLOS ONE 11, e0164012. doi:10.1371/journal.pone.0164012.

Valdesolo, P., and DeSteno, D. (2006). Manipulations of emotional context shape moral judgment. Psychol. Sci. 17, 476-477. doi:10.1111/j.1467-9280.2006.01731.x.

Waldmann, M. R., Nagel, J., and Wiegmann, A. (2012). "Moral judgment," in The Oxford handbook of thinking and reasoning, eds. K. J. Holyoak and R. G. Morrison (New York, NY: Oxford University Press), 364-389. Available at: https://www.psych.unigoettingen.de/de/cognition/publikationendateiennagel/2012_WaldmannNagelWiegmann_Moral \%20judgment_.pdf [Accessed July 8, 2015].
Wang, C. S., Sivanathan, N., Narayanan, J., Ganegoda, D. B., Bauer, M., Bodenhausen, G. V., et al. (2011). Retribution and emotional regulation: The effects of time delay in angry economic interactions. Organ. Behav. Hum. Decis. Process. 116, 46-54. doi:10.1016/j.obhdp.2011.05.007.

Wiegmann, A., and Waldmann, M. R. (2014). Transfer effects between moral dilemmas: A causal model theory. Cognition 131, 28-43. doi:10.1016/j.cognition.2013.12.004.

Williams, K. M., Nathanson, C., and Paulhus, D. L. (2003). Structure and validity of the self-report psychopathy scale-III in normal populations. in (Toronto, CA). Available at: http://www2.psych.ubc.ca/ dpaulhus/research/d ark_triad/presentations/apa03_kevin_SRP_post er.pdf [Accessed May 12, 2015].

Young, L., Koenigs, M., Kruepke, M., and Newman, J. P. (2012). Psychopathy increases perceived moral permissibility of accidents. J. Abnorm. Psychol. 121, 659-667. doi:10.1037/a0027489. 


\section{Tables}

Table 1. Results of exploratory factor analysis

\begin{tabular}{|c|c|c|c|c|c|c|}
\hline \multirow{2}{*}{ Entered Personality Facets } & \multicolumn{5}{|c|}{ Extracted Personality Domains } & \multirow{2}{*}{$\begin{array}{c}\text { Communalities } \\
h^{2}\end{array}$} \\
\hline & PF1 & PF2 & PF3 & PF4 & PF5 & \\
\hline Altruism (NEO-PI-R) & .478 & -.246 & -.441 & .000 & .149 & .651 \\
\hline Neuroticism (NEO-FFI) & .187 & .790 & .155 & .159 & .145 & .759 \\
\hline Victim justice sensitivity (USS-8) & -.340 & -.024 & .094 & .665 & .435 & .644 \\
\hline Observer justice sensitivity (USS-8) & .111 & -.019 & .022 & .793 & -.095 & .683 \\
\hline Beneficiary justice sensitivity (USS-8) & .045 & .117 & -.021 & .707 & -.165 & .576 \\
\hline Perpetrator justice sensitivity (USS-8) & .065 & .020 & -.426 & .436 & -.243 & .564 \\
\hline Faith in intuition (REI) & .458 & -.327 & .193 & .066 & .563 & .656 \\
\hline Need for cognition (REI) & .096 & -.288 & .145 & .149 & -.757 & .696 \\
\hline Obedience to Authorities & -.049 & .141 & -.141 & -.125 & .694 & .509 \\
\hline Self-esteem & .002 & -.798 & .124 & -.062 & -.055 & .706 \\
\hline Interpersonal manipulation (SRP-III) & .049 & -.020 & .845 & .027 & -.007 & .678 \\
\hline Callous affect (SRP-III) & -.410 & .023 & .605 & -.059 & -.105 & .751 \\
\hline Erratic life-style (SRP-III) & .261 & -.073 & .762 & .047 & -.176 & .511 \\
\hline Fantasy (IRI-SPF) & .807 & .234 & .301 & -.015 & .020 & .560 \\
\hline Empathic concern (IRI-SPF) & .722 & .191 & -.108 & .138 & -.012 & .708 \\
\hline Perspective taking (IRI-SPF) & .645 & .043 & .025 & -.083 & -.282 & .441 \\
\hline \multirow[t]{2}{*}{ Personal distress (IRI-SPF) } & .181 & .781 & -.047 & -.090 & .125 & .628 \\
\hline & PF1 & PF2 & PF3 & PF4 & PF5 & Total \\
\hline Domain Eigenvalues $(\lambda)$ & 3.94 & 2.67 & 1.57 & 1.47 & 1.08 & \\
\hline Variance proportion $(\%)$ per domain & 23.18 & 15.69 & 9.24 & 8.63 & 6.33 & 63.07 \\
\hline Domain correlation matrix & PF1 & PF2 & PF3 & PF4 & PF5 & \\
\hline PF1 & 1.00 & -.11 & -.37 & .37 & .02 & \\
\hline $\mathrm{PF} 2$ & & 1.00 & -.07 & .20 & .13 & \\
\hline PF3 & & & 1.00 & -.23 & .12 & \\
\hline PF4 & & & & 1.00 & .11 & \\
\hline PF5 & & & & & 1.00 & \\
\hline
\end{tabular}


Table 2. Descriptive statistics and correlations of outcome variables

\begin{tabular}{|c|c|c|c|c|c|c|c|c|}
\hline & \multicolumn{3}{|c|}{ Descriptive Statistics $M(S D)$} & \multicolumn{5}{|c|}{ Repeated-measures correlations } \\
\hline Outcome & Architect & Footbridge & Lifeboat & 1. & 2. & 3. & 4. & 5. \\
\hline $\begin{array}{l}\text { 1. Punishment } \\
\text { (imprisonment } \\
\text { in years) }\end{array}$ & $\begin{array}{l}24.67 \\
(7.43)\end{array}$ & $\begin{array}{l}5.58 \\
(2.85)\end{array}$ & $\begin{array}{l}3.94 \\
(2.55)\end{array}$ & 1 & $.58^{* * *}$ & $-.76^{* * *}$ & $-.75^{* * *}$ & $-.51^{* * *}$ \\
\hline $\begin{array}{l}\text { 2. Negative Emo- } \\
\text { tions }\end{array}$ & $\begin{array}{c}3.12 \\
(1.05)\end{array}$ & $\begin{array}{c}2.38 \\
(1.02)\end{array}$ & $\begin{array}{c}2.22 \\
(0.86)\end{array}$ & & 1 & $-.56^{* * *}$ & $-.56^{* * *}$ & $-.32^{* * *}$ \\
\hline $\begin{array}{l}\text { 3. Understanding } \\
\text { Emotions }\end{array}$ & $\begin{array}{c}0.76 \\
(0.98)\end{array}$ & $\begin{array}{c}2.39 \\
(1.33)\end{array}$ & $\begin{array}{c}3.47 \\
(1.31)\end{array}$ & & & 1 & $.82^{* * *}$ & $.39^{* * *}$ \\
\hline 4. Appropriateness & $\begin{array}{c}0.19 \\
(0.62)\end{array}$ & $\begin{array}{c}1.77 \\
(1.41)\end{array}$ & $\begin{array}{l}2.85 \\
(1.26)\end{array}$ & & & & 1 & $.34^{* * *}$ \\
\hline $\begin{array}{l}\text { 5. Decision Diffi- } \\
\text { culty }\end{array}$ & $\begin{array}{l}1.29 \\
(1.56)\end{array}$ & $\begin{array}{l}3.05 \\
(2.06)\end{array}$ & $\begin{array}{l}2.79 \\
(2.01)\end{array}$ & & & & & 1 \\
\hline
\end{tabular}

Note: ${ }^{* * *} p<.0001$, two-tailed, Bonferroni-corrected. 
Table 3. Correlations of experimental outcomes and personality domains $(N=1004)$

\begin{tabular}{|c|c|c|c|c|c|c|c|c|c|c|c|c|c|}
\hline & & \multicolumn{4}{|c|}{ Architect } & \multicolumn{4}{|c|}{ Footbridge } & \multicolumn{4}{|c|}{ Lifeboat } \\
\hline & & Punishment & $\begin{array}{l}\text { Negative } \\
\text { Emotions }\end{array}$ & $\begin{array}{c}\text { Under- } \\
\text { standing } \\
\text { Emotions }\end{array}$ & $\begin{array}{c}\text { Appropriate- } \\
\text { ness }\end{array}$ & Punishment & $\begin{array}{l}\text { Negative } \\
\text { Emotions }\end{array}$ & $\begin{array}{c}\text { Under- } \\
\text { standing } \\
\text { Emotions }\end{array}$ & $\begin{array}{c}\text { Appropriate- } \\
\text { ness }\end{array}$ & Punishment & $\begin{array}{l}\text { Negative } \\
\text { Emotions }\end{array}$ & $\begin{array}{c}\text { Under- } \\
\text { standing } \\
\text { Emotions }\end{array}$ & $\begin{array}{c}\text { Appropriate- } \\
\text { ness }\end{array}$ \\
\hline \multirow[t]{4}{*}{ Architect } & Punishment & - & & & & & & & & & & & \\
\hline & Negative emotions & $.08^{*}$ & - & & & & & & & & & & \\
\hline & $\begin{array}{l}\text { Understanding } \\
\text { emotions }\end{array}$ & $-.16^{* * *}$ & -.07 & - & & & & & & & & & \\
\hline & Appropriateness & $-.10^{*}$ & $-.10^{*}$ & $.39^{* * *}$ & - & & & & & & & & \\
\hline \multirow[t]{4}{*}{ Footbridge } & Punishment & $.24^{* * *}$ & -.01 & .00 & -.01 & - & & & & & & & \\
\hline & Negative emotions & .03 & $.35^{* * *}$ & -.03 & -.04 & $.17^{* * *}$ & - & & & & & & \\
\hline & $\begin{array}{l}\text { Understanding } \\
\text { emotions }\end{array}$ & -.05 & .10 & $.13^{* * *}$ & .01 & $-.35^{* * *}$ & $-.11^{* * * *}$ & - & & & & & \\
\hline & Appropriateness & -.03 & -.02 & $.20^{* * * *}$ & $.17^{* * * *}$ & $-.28^{* * *}$ & $-.20^{* * *}$ & $.42^{* * * *}$ & - & & & & \\
\hline \multirow[t]{4}{*}{ Lifeboat } & Punishment & $.15^{* * *}$ & .00 & .04 & .04 & $.31^{* * *}$ & .08 & $-.12^{* * *}$ & -.06 & - & & & \\
\hline & Negative emotions & .02 & $.39^{* * *}$ & -.00 & -.02 & .06 & $.44^{* * *}$ & .02 & -.08 & $.13^{* * *}$ & - & & \\
\hline & $\begin{array}{l}\text { Understanding } \\
\text { emotions }\end{array}$ & -.02 & .08 & $.12^{* * *}$ & .03 & $-.13^{* * * *}$ & -.02 & $.30^{* * * *}$ & $.17^{* * * *}$ & $-.26^{* * *}$ & -.03 & - & \\
\hline & Appropriateness & -.01 & -.03 & $.18^{* * *}$ & $.16^{* * *}$ & -.07 & $-.09^{*}$ & $.16^{* * * *}$ & $.33^{* * *}$ & $-.22^{* * *}$ & $-.16^{* * *}$ & $.49^{* * *}$ & - \\
\hline \multirow[t]{5}{*}{ Personality } & PF1 & -.01 & $.30^{* * *}$ & $-.11^{* * *}$ & $-.12^{* * *}$ & -.04 & $.22^{* * *}$ & .00 & $-.18^{* * *}$ & -.04 & $.27^{* * *}$ & -.01 & $-.17^{* * *}$ \\
\hline & PF2 & -.05 & -.00 & .01 & .00 & -.02 & .06 & -.04 & .01 & -.01 & .03 & -.06 & -.05 \\
\hline & PF3 & $.13^{* * * *}$ & -.07 & $.31^{* * *}$ & $.22^{* * *}$ & $.18^{* * * *}$ & -.07 & .00 & $.24^{* * * *}$ & $.24^{* * *}$ & -.07 & .00 & $.22^{* * *}$ \\
\hline & PF4 & -.02 & $.14^{* * *}$ & -.07 & -.06 & -.03 & $.15^{* * *}$ & -.01 & -.06 & -.03 & $.14^{* * * *}$ & .00 & -.07 \\
\hline & PF5 & .02 & .01 & -.03 & $.09^{*}$ & $.18^{* * *}$ & $.17^{* * *}$ & $-.28^{* * *}$ & .00 & $.11^{* * *}$ & $.12^{* * *}$ & $-.12^{* * *}$ & -.01 \\
\hline
\end{tabular}

Note: Kendall's $\tau$ rank correlations, ${ }^{*} p<3.97 \mathrm{e}-4,{ }^{* *} p<7.94 \mathrm{e}-5,{ }^{* * *} p<7.94 \mathrm{e}-6$, two-tailed, Bonferroni-corrected. 
Table 4. Results of repeated measurement ANOVAs contrasting selfish (architect) and utilitarian (footbridge) reason to kill (N $=1004)$

\begin{tabular}{|c|c|c|c|c|c|c|c|c|c|c|c|c|c|c|c|c|c|c|c|c|c|c|c|c|}
\hline \multirow[b]{2}{*}{$\begin{array}{l}\text { Model } \\
\text { factors }\end{array}$} & \multicolumn{4}{|c|}{ Imprisonment duration (years) } & \multicolumn{7}{|c|}{ Negative Emotions [0,6] } & \multicolumn{7}{|c|}{ Understanding Emotions $[0,6]$} & \multicolumn{6}{|c|}{ Perceived moral appropriateness $[0,6]$} \\
\hline & $b$ & $S E$ & $\beta$ & $t$ & $p$ & $\eta_{\mathrm{p}}^{2}$ & $b$ & $S E$ & $\beta$ & $t$ & $p$ & $\eta_{\mathrm{p}}^{2}$ & $b$ & $S E$ & $\beta$ & $t$ & $p$ & $\eta_{\mathrm{p}}^{2}$ & $b$ & $S E$ & $\beta$ & $t$ & $p$ & $\eta_{\mathrm{p}}^{2}$ \\
\hline Intercept & 5.58 & 0.17 & & 32.05 & $<.001$ & & 2.38 & 0.03 & & 80.54 & $<.001$ & & 2.39 & 0.03 & & 71.62 & $<.001$ & & 1.77 & 0.03 & & 55.47 & $<.001$ & \\
\hline Scenario & 19.09 & 0.22 & .86 & 87.82 & $<.001$ & .83 & 0.74 & 0.03 & .34 & 23.37 & $<.001$ & .28 & -1.63 & 0.04 & -.57 & 37.84 & $<.001$ & .46 & -1.59 & 0.04 & -.59 & $\begin{array}{c}- \\
36.37\end{array}$ & $<.001$ & .41 \\
\hline PF1 & 0.05 & 0.20 & .00 & 0.26 & .793 & .00 & 0.31 & 0.03 & .28 & 9.10 & $<.001$ & .12 & 0.02 & 0.04 & .02 & 0.57 & .569 & .00 & -0.24 & 0.04 & -.18 & -6.54 & $<.001$ & .01 \\
\hline PF2 & -0.08 & 0.18 & -.01 & -0.43 & .665 & .00 & 0.09 & 0.03 & .08 & 2.76 & .006 & .00 & -0.03 & 0.04 & -.02 & -0.80 & .423 & .00 & 0.00 & 0.03 & .00 & -0.10 & .924 & .00 \\
\hline $\mathrm{PF} 3$ & 0.74 & 0.19 & .07 & 3.85 & $<.001$ & .02 & -0.01 & 0.03 & -.01 & -0.27 & .785 & .00 & 0.06 & 0.04 & .04 & 1.74 & .083 & .05 & 0.41 & 0.04 & .30 & 11.61 & $<.001$ & .07 \\
\hline PF4 & -0.02 & 0.20 & .00 & -0.08 & .938 & .00 & 0.07 & 0.03 & .06 & 1.97 & .049 & .00 & 0.04 & 0.04 & .03 & 1.08 & .278 & .00 & 0.02 & 0.04 & .02 & 0.60 & .549 & .00 \\
\hline PF5 & 0.72 & 0.18 & .06 & 4.03 & $<.001$ & .01 & 0.23 & 0.03 & .21 & 7.58 & $<.001$ & .01 & -0.55 & 0.03 & -.39 & 16.17 & $<.001$ & .07 & -0.04 & 0.03 & -.03 & -1.33 & .182 & .00 \\
\hline $\begin{array}{l}\text { Scenario } \\
\times \text { PF1 }\end{array}$ & 0.00 & 0.25 & .00 & 0.00 & 1.000 & .00 & 0.16 & 0.04 & .10 & 4.43 & $<.001$ & .01 & 0.00 & 0.05 & .00 & 0.09 & .928 & .00 & 0.22 & 0.05 & .11 & 4.28 & $<.001$ & .01 \\
\hline $\begin{array}{l}\text { Scenario } \\
\times \text { PF2 }\end{array}$ & -0.49 & 0.23 & -.03 & -2.15 & .031 & .00 & -0.04 & 0.03 & -.03 & -1.26 & .207 & .00 & 0.08 & 0.05 & .04 & 1.72 & .086 & .00 & 0.01 & 0.05 & .00 & 0.14 & .892 & .00 \\
\hline $\begin{array}{l}\text { Scenario } \\
\times \mathrm{PF} 3\end{array}$ & 0.30 & 0.24 & .02 & 1.27 & .205 & .00 & 0.06 & 0.03 & .04 & 1.61 & .107 & .00 & 0.39 & 0.05 & .20 & 8.32 & $<.001$ & .04 & -0.21 & 0.05 & -.11 & -4.27 & $<.001$ & .01 \\
\hline $\begin{array}{l}\text { Scenario } \\
\times \text { PF4 }\end{array}$ & 0.03 & 0.24 & .00 & 0.12 & .908 & .00 & -0.02 & 0.04 & -.01 & -0.58 & .560 & .00 & -0.03 & 0.05 & -.01 & -0.62 & .535 & .00 & -0.01 & 0.05 & -.01 & -0.27 & .790 & .00 \\
\hline $\begin{array}{l}\text { Scenario } \\
\times \text { PF5 }\end{array}$ & -0.63 & 0.22 & -.04 & -2.81 & .005 & .00 & -0.23 & 0.03 & -.14 & -6.94 & $<.001$ & .03 & 0.50 & 0.04 & .25 & 11.31 & $<.001$ & .07 & 0.08 & 0.04 & .04 & 1.88 & .061 & .00 \\
\hline $\begin{array}{l}\text { Overall } \\
\text { model } \\
\text { statistic }\end{array}$ & $F(11,1$ & 4.44) $=$ & .63, & $2 \mathrm{e}-16^{*}$ &,$R^{2}=.807$ & & $F(11,1$ & 4.44) $=$ & $.90, p$ & $2.2 \mathrm{e}-16^{* *}$ & $R^{2}=.586$ & & $F(11,1$ & $4.40)=$ & $1.40, p$ & $2.2 \mathrm{e}-16$ & $R^{2}=.542$ & & $F(11,1$ & 4.44) $=$ & 49.14, & $2.2 \mathrm{e}-16$ & $R^{2}=.477$ & \\
\hline
\end{tabular}


Table 5. Results of repeated measurement ANOVAs contrasting utilitarian killing with avoidable (footbridge) and inevitable harm (lifeboat) $(N=1004)$

\begin{tabular}{|c|c|c|c|c|c|c|c|c|c|c|c|c|c|c|c|c|c|c|c|c|c|c|c|c|}
\hline \multirow[b]{2}{*}{$\begin{array}{l}\text { Model } \\
\text { factors }\end{array}$} & \multicolumn{4}{|c|}{ Imprisonment duration (years) } & \multicolumn{7}{|c|}{ Negative Emotions $[\mathbf{0 , 6 ]}$} & \multicolumn{6}{|c|}{ Understanding Emotions $[0,6]$} & \multicolumn{6}{|c|}{ Perceived moral appropriateness $[0,6]$} & \multirow[b]{2}{*}{$\eta_{\mathrm{p}}^{2}$} \\
\hline & $b$ & $S E$ & $\beta$ & $t$ & $p$ & $\eta_{\mathrm{p}}^{2}$ & $b$ & $S E$ & $\beta$ & $t$ & $p$ & $\eta_{\mathrm{p}}^{2}$ & $b$ & $S E$ & $\beta$ & $t$ & $p$ & $\eta_{\mathrm{p}}^{2}$ & $b$ & $S E$ & $\beta$ & $t$ & $p$ & \\
\hline Intercept & 3.94 & 0.08 & & 49.26 & $<.001$ & & 2.22 & 0.03 & & 82.11 & $<.001$ & & 3.47 & 0.04 & & 87.90 & $<.001$ & & 2.85 & 0.04 & & 72.23 & $<.001$ & \\
\hline Scenario & 1.64 & 0.09 & .29 & 17.89 & $<.001$ & .18 & 0.15 & 0.03 & .08 & 5.58 & $<.001$ & .02 & -1.08 & 0.04 & -.38 & 24.31 & $<.001$ & .29 & -1.07 & 0.05 & -.37 & 23.53 & $<.001$ & .27 \\
\hline PF1 & 0.09 & 0.09 & .03 & 0.98 & .325 & .00 & 0.34 & 0.03 & .36 & 10.65 & $<.001$ & .10 & 0.01 & 0.05 & .01 & 0.22 & .826 & .00 & -0.20 & 0.05 & -.14 & -4.46 & $<.001$ & .02 \\
\hline PF2 & 0.03 & 0.08 & .01 & 0.30 & .764 & .00 & 0.06 & 0.03 & .06 & 2.15 & .032 & .01 & -0.07 & 0.04 & -.05 & -1.75 & .081 & .00 & -0.06 & 0.04 & -.04 & -1.39 & .164 & .00 \\
\hline PF3 & 0.77 & 0.09 & .27 & 8.73 & $<.001$ & .07 & 0.03 & 0.03 & .03 & 0.89 & .376 & .00 & 0.02 & 0.04 & .01 & 0.35 & .725 & .00 & 0.32 & 0.04 & .22 & 7.34 & $<.001$ & .07 \\
\hline PF4 & 0.02 & 0.09 & .01 & 0.21 & .836 & .00 & 0.02 & 0.03 & .02 & 0.60 & .550 & .00 & 0.04 & 0.04 & .03 & 0.89 & .375 & .00 & 0.05 & 0.04 & .03 & 1.03 & .302 & .00 \\
\hline PF5 & 0.23 & 0.08 & .08 & 2.78 & .005 & .03 & 0.11 & 0.03 & .12 & 4.07 & $<.001$ & .04 & -0.27 & 0.04 & -.19 & -6.57 & $<.001$ & .09 & -0.05 & 0.04 & -.03 & -1.16 & .246 & .00 \\
\hline $\begin{array}{l}\text { Scenario } \\
\times \text { PF1 }\end{array}$ & -0.04 & 0.11 & -.01 & -0.36 & .718 & .00 & -0.02 & 0.03 & -.02 & -0.74 & .462 & .00 & 0.01 & 0.05 & .01 & 0.23 & .816 & .00 & -0.04 & 0.05 & -.02 & -0.74 & .462 & .00 \\
\hline $\begin{array}{l}\text { Scenario } \\
\times \text { PF2 }\end{array}$ & -0.11 & 0.10 & -.03 & -1.09 & .278 & .00 & 0.02 & 0.03 & .02 & 0.85 & .395 & .00 & 0.04 & 0.05 & .02 & 0.95 & .343 & .00 & 0.05 & 0.05 & .03 & 1.14 & .256 & .00 \\
\hline $\begin{array}{l}\text { Scenario } \\
\times \mathrm{PF} 3\end{array}$ & -0.03 & 0.10 & -.01 & -0.31 & .759 & .00 & -0.04 & 0.03 & -.03 & -1.17 & .241 & .00 & 0.05 & 0.05 & .02 & 0.99 & .323 & .00 & 0.09 & 0.05 & .04 & 1.80 & .072 & .00 \\
\hline $\begin{array}{l}\text { Scenario } \\
\times \text { PF4 }\end{array}$ & -0.03 & 0.10 & -.01 & -0.33 & .742 & .00 & 0.05 & 0.03 & .04 & 1.53 & .126 & .00 & 0.00 & 0.05 & .00 & 0.03 & .979 & .00 & -0.02 & 0.05 & -.01 & -0.47 & .637 & .00 \\
\hline $\begin{array}{l}\text { Scenario } \\
\times \text { PF5 }\end{array}$ & 0.49 & 0.09 & .12 & 5.22 & $<.001$ & .02 & 0.12 & 0.03 & .09 & 4.14 & $<.001$ & .01 & -0.29 & 0.05 & -.14 & -6.30 & $<.001$ & .03 & 0.00 & 0.05 & .00 & 0.07 & .947 & .00 \\
\hline $\begin{array}{l}\text { Overall } \\
\text { model } \\
\text { statistic }\end{array}$ & $F(11$, & $4.44)=$ & $46, p$ & $2 \mathrm{e}-16^{* *}$ & $R^{2}=.474$ & & $F(11,1$ & 14.44) $=$ & $39, p$ & $2 \mathrm{e}-16^{* *}$ & $R^{2}=.583$ & & $F(11$, & $4.44)=$ & $1.86, p$ & $2.2 \mathrm{e}-16^{*}$ & $R^{2}=.515$ & & $F(11,1$ & 4.44) $=$ & $.40, p$ & $2 \mathrm{e}-16^{*}$ & $R^{2}=.499$ & \\
\hline
\end{tabular}


12 Figures
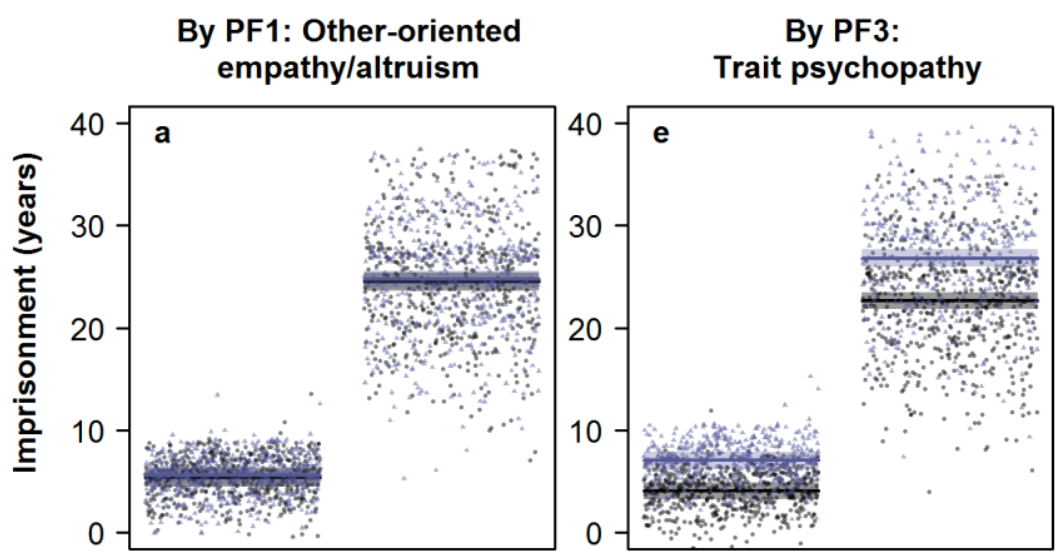

By PF5: Intuitive/authorityobedient thinking vs. Need for cognition


Figure 1. Punitive, emotional, and cognitive responses (see rows) to selfish murder (architect) and utilitarian killing (footbridge) depending on observers' personality characteristics (see columns). Lower $(M-2 S D)$ and higher values $(M+2 S D)$ of the respective personality characteristic are indicated by black and light grey color, respectively. 

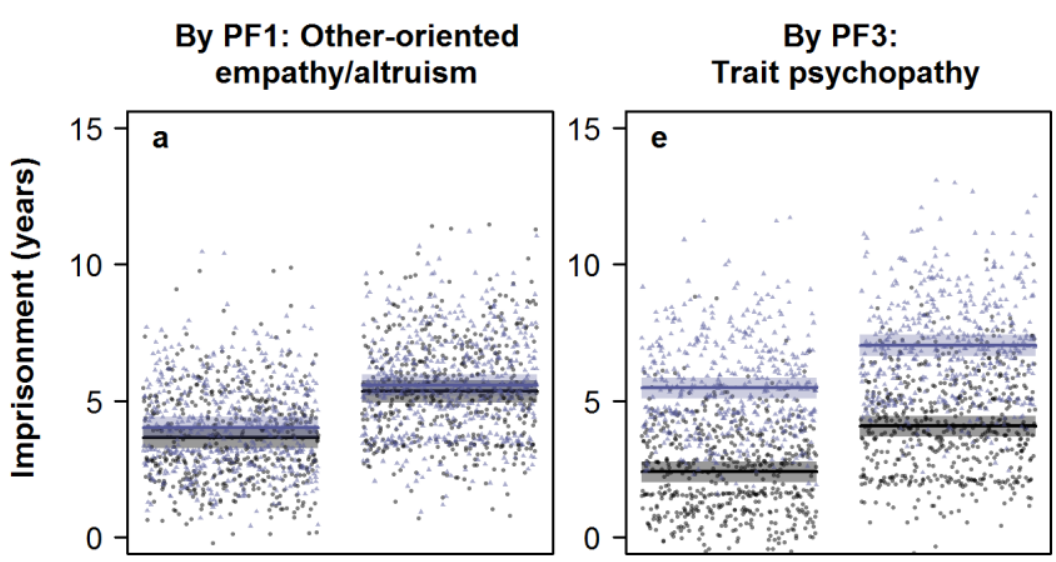
By PF5: Intuitive/authority- obedient thinking vs. Need for cognition
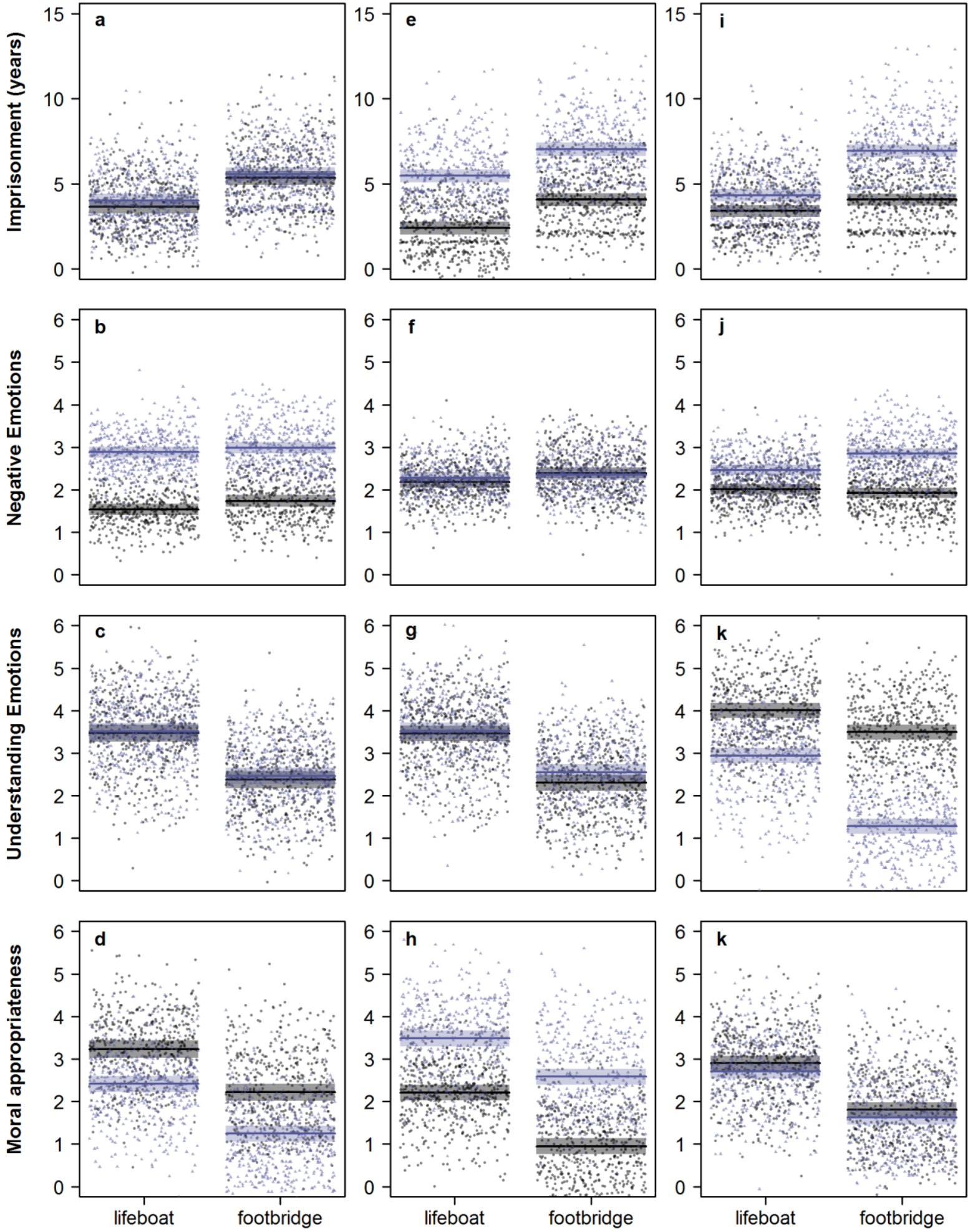

Figure 2. Punitive, emotional, and cognitive responses (see columns) to utilitarian killings causing inevitable harm to the victim(s) (lifeboat) vs. avoidable harm to the victim (footbridge) depending on observers' personality differences (see rows). Lower $(M-2 S D)$ and higher values $(M+2 S D)$ of the respective personality domain are indicated by black and light grey color, respectively. 